\title{
Reaktif etilen terpolimerlerin bitümün modifikasyonunda kullanımı: Bir literatür araştırması
}

\author{
The use of reactive ethylene terpolymers in the modification of bitumen: A literature review
}

\author{
Aytuğ KUMANDAŞ ${ }^{* 1, a}$, Erman ÇAVDAR ${ }^{2, b}$, Erhan Burak PANCAR ${ }^{1, c}$, Şeref ORUÇ ${ }^{2, d}$ \\ ${ }^{1}$ Ondokuz Mayı Üniversitesi, Mühendislik Fakültesi, İnşaat Mühendisliği Bölümü, 55139, Samsun \\ ${ }^{2}$ Karadeniz Teknik Üniversitesi, Mühendislik Fakültesi, İnșaat Mühendisliği Bölümü, 61080, Trabzon
}

• Geliş tarihi / Received: 15.03.2021 • Düzeltilerek geliş tarihi / Received in revised form: 18.05.2021 • Kabul tarihi / Accepted: 24.05 .2021

\section{$\ddot{O} z$}

Uzun yıllardan beri, bitümün performansının arttırılması amacıyla bitüme farklı katkı maddeleri ilave edilerek modifiye edilmektedir. Bitüm modifikasyonunda kullanılan ve bitüm ile tepkimeye girdiği varsayılan reaktif etilen terpolimerler (RET) diğer katkı malzemelerine kıyasla nispeten daha günceldir. Bu katkı malzemelerinin en önemli özellikleri diğer katkı malzemelerinde meydana gelen faz ayrışımına maruz kalmaması ve diğer katkı maddelerine kıyasla çok daha az miktarlarda (\%1-2) bitüme ilave edilmesidir. Bu derleme çalışmasında, RET modifiye bitüm kullanılan çalışmalar incelenmiş ve RET modifikasyonun bitüm üzerindeki etkisi anlaşılmaya çalışılmıştır. Bu doğrultuda, öncelikle RET'ler ile ilgili genel bilgilere ve karıştırma koşullarına değinilmiş ardından RET modifikasyonunun bitümün fiziksel ve reolojik özelliklerine etkisi incelenmiştir. Bunlara ilaveten, RET modifiyeli bitümler ile hazırlanan asfalt karışımlar üzerine yapılan çalışmalar ve kompozit modifikasyon içerisinde RET'e yer verilen çalışmalar da incelenmiştir. Yapılan araştırma sonucunda, RET modifikasyonunun saf bitümün sertliğini ve yüksek sıcaklıklardaki performansını arttırdığı anlaşılmıştır. Bununla birlikte, RET modifiyeli bitümlerin hazırlanmasında kullanılan karıştırma koşullarının önemli farklılıklar gösterdiği fark edilmiştir. Ayrıca, kompozit modifikasyonda RET ile birlikte farklı katkı maddelerinin kullanımı ile saf bitüme kıyasla düşük sıcaklıklarda daha esnek, yüksek sıcaklıklarda ise daha rijit bir bitümün elde edilmesinin mümkün olduğu görülmüştür.

Anahtar kelimeler: Bitüm modifikasyonu, Bitüm reolojisi, Karıştırma koşulları, Reaktif etilen terpolimer

\begin{abstract}
For many years, bitumen has been modified by adding different additives in order to increase its performance. Reactive ethylene terpolymers (RET) used in bitumen modification and assumed to react with bitumen are relatively more up-todate compared to other additives. The most important features of these additives are that they are not exposed to phase separation occurring in other additives and they are added to bitumen in much smaller amounts (1-2\%) compared to other additives. In this review, the studies using RET modified bitumen were examined and the effect of RET modification on bitumen was tried to be understood. Accordingly, first of all, general information about RETs and mixing conditions were mentioned and then the effect of RET modification on physical and rheological properties of bitumen was examined. In addition, studies on asphalt mixtures prepared with RET modified bitumens and studies involving RET in composite modification were also examined. As a result of this review study, it was understood that the RET modification increased the hardness and performance of pure bitumen at high temperatures. However, it has been noticed that the mixing conditions used in the preparation of RET modified bitumen differ significantly. In addition, it has been observed that it is possible to obtain a bitumen that is more flexible at low temperatures and more rigid at high temperatures compared to pure bitumen, with the use of different additives together with RET in composite modification.
\end{abstract}

Keywords: Bitumen modification, Bitumen rheology, Mixing conditions, Reactive ethylene terpolymer

\footnotetext{
*a Aytuğ KUMANDAŞ; aytug.kumandas@omu.edu.tr; Tel: (0362) 312 19 19; orcid.org/0000-0003-1765-9963

${ }^{\mathrm{b}}$ orcid.org/0000-0002-0238-5245 $\quad{ }^{\mathrm{c}}$ orcid.org/0000-0002-7958-3434 $\quad{ }^{\mathrm{d}}$ orcid.org/0000-0001-5788-890X
} 


\section{Giriş}

Bitüm en eski yap1 malzemelerinden biridir ve antik çağlardan beri çok değerlidir (Connan vd., 1999). Genel olarak bitümler karmaşık bir içyapıya sahip yapı malzemeleridir. Bitümün, asfaltenler ve maltenler ile temsil edildiği ve farklı seviyelerde polarite ve molar kütlelere sahip kompleks bileşiklerin bir koloidal sistemi olduğu kabul edilmektedir (Jasso vd., 2015). Asfalt karışımlarda kullanılan bitümler, geniş bir sıcaklık rejimi altında yeterli performansı göstermelidirler. Geleneksel bitüm kullanılarak inşa edilen asfalt kaplamalar, çoğu karayolu kaplamlarında ve havaalanı pisti uygulamalarında tatmin edici bir performans sergilemiştir (Airey, 2002). Ancak, karayolu trafiğinin hacmindeki, dingil yüklerindeki ve tekerlek lastiklerinin basınçlarındaki artış, yetersiz bakım yapılması, iklim koşullarının değişmesi, inşaat ve tasarım hataları asfalt kaplamaların bozulmasına sebep olarak hizmet ömrünü olumsuz etkilemektedir (Airey, 2002; Isacsson ve Lu, 1995; Oruc vd., 2016; Suo ve Wong, 2009; Tayfur vd., 2007). Bunun yanı sıra, yaşam standartlarındaki artış, sosyal gelişme, mevcut kaynakların yetersizliği, artan malzeme ve enerji maliyeti karayolu mühendislerini yeni yollar inşa etmeye ve mevcut yolları iyileştirme konusunda yeni alternatifler keşfetmeye yöneltmiştir (Al-Hadidy ve Tan, 2009; Sengoz ve Topal, 2005; Yilmaz vd., 2011).

Bitüm modifikasyonu, bitümün eksikliklerini gidermek ve böylece asfalt kaplamaların performansını arttırmak için bir çözüm sunmaktadır (Isacsson ve Lu, 1995). Bilinen en iyi modifikasyon şekli, bitümün sertliğini, yüksek servis sıcaklıklarında arttırarak ve düşük servis sicaklıklarında ise azaltarak bitümün sicaklığa karşı duyarlılığını geliştirmek amacıyla kullanılan polimer modifikasyonudur (Brule vd., 1988; Collins vd., 1991; Connan vd., 1999). Polimer modifiyeli bitümler (PMB'ler) kaplamanın tekerlek izine, soyulmaya, yorulma ve 1si etkisiyle meydana gelen çatlaklara karşı direncinin artmasını ve sicaklık hassasiyetinin azalmasını sağlamaktadır. PMB'ler ile oluşturulan asfalt kaplamalar, yoğun caddelerdeki kavşaklar, havaalanları, araç tartım istasyonları ve yarış pistleri gibi yüksek gerilmelerin meydana geldiği yerlerde başarı ile kullanılmaktadır. Bitümü modifiye etmek için kullanılan polimerler arasında stiren-bütadien-stiren (SBS), stiren-bütadien kauçuğu (SBR), Elvaloy, kauçuk, etilen-vinilasetat (EVA), polietilen ve diğerleri bulunmaktadır (Y1ldırım, 2007).
Bitüm modifikasyonunda kullanılan polimerler genellikle, elastomerler ve plastomer olmak üzere iki gruba ayrılırlar ve bunların ortak dezavantaj1 yüksek sıcaklıklarda faz ayrışımına uğramalarıdır. $\mathrm{Bu}$ durumun sebebinin, bu katk1 malzemelerinin bitüm ile kimyasal bir etkileşimden ziyade fiziksel bir etkileşime geçmeleri olduğu düşünülebilir. Bu husustan yola çıkarak araştırmacılar, polimer modifiye malzemelerinin üçüncü grubu olarak sınıflandırmaya dâhil edilen ve bitüm ile kimyasal bir tepkimeye girdiği varsayılan reaktif polimerleri üretmiştir. Reaktif etilen terpolimerler (RET) ile bitüm arasındaki iyi uyumluluk ve kimyasal bağ sadece çeşitli performans parametrelerini iyileştirmekle kalmayıp yüksek sıcaklıkta depolama koşullarında faz ayrışmasını da önlemektedir (Jasso vd., 2015; Polacco vd., 2004a; Polacco vd., 2004b; Yildırım, 2007). Araştırmacılar bunlara ek olarak bitüme RET ilavesinin elastik geri dönmeyi iyileştirdiğini, sıcaklık hassasiyetini ve nem hasarını azalttığını tespit etmişlerdir (Domingos ve Faxina, 2015b; Topal, 2010; Y1ldırım, 2007). Bitüm modifikasyonunda polimerlerin yaklaşı $\% 5$ oranında kullanılmasına rağmen RET'ler için bu oran yaklaşı \% $\%$-2 civarına düşmektedir ve RET modifiyeli bitümlerin (RETMB) yüksek sıcaklıklardaki performansı diğer PMB'lerle yaklaşık olarak denktir. $\mathrm{Bu}$ durum, RET'lerin bitüm modifikasyonunda daha ekonomik bir katk1 maddesi olabileceği fikrini ortaya çıkarmaktadır. Buna ilaveten, diğer katk1 maddelerinin bir dezavantajı olan depolama esnasındaki faz ayrışımı RET'lerde meydana gelmemektedir. $\mathrm{Bu}$ hususlardan yola çıkılarak, RETMB'lerin daha detaylı bir şekilde anlaşılması amacıyla bu derleme çalışması hazırlanmıştır.

Bu çalışmada, RETMB'lerin, fiziksel ve reolojik özellikleri ile ilgili yapılan çalışmalar detaylı bir şekilde incelenip RET modifikasyonunun bitüm üzerindeki etkilerinin araştırılması amaçlanmıştır. $\mathrm{Bu}$ amaç doğrultusunda öncelikle RET'ler ile ilgili literatürden elde edinilen genel bilgiler paylaşılmış, ardından literatürdeki çalışmalar göz önüne alınarak, RETMB'lerin hazırlanma koşulları, RET modifikasyonunun bitümün fiziksel ve reolojik özelliklerine etkisi ve RETMB'lerle hazırlanan asfalt karışım numunelerinin performansları incelenmiştir. Bunlara ilaveten, RETMB'lere başka katkı malzemelerinin ilave edilmesiyle hazırlanan kompozit modifiyeli bitümlerle ilgili yapılan çalışmalara da değinilmiştir. 


\section{Metodoloji}

Bu çalışmada, Web of Science, Scopus ve Google Akademik veri tabanlarında yayınlanmış olan yayınlar incelenmiştir. Belirtilen veri tabanlarında, "Elvaloy", "reactive ethylene terpolymer", "Elvaloy 4170", "Elvaloy 5160", "asphalt", "asphalt modification", "bitumen", "bitumen modification" kelimeleri ayrı ayrı veya bazılarının kombinasyonu şeklinde (örneğin "Elvaloy" + "asphalt") aratılarak bir literatür taraması gerçekleştirilmiştir. Elvaloy, RET'lerin bitüm modifikasyonunda en yaygın kullanılan ürünüdür ve bu sebeple anahtar kelimelerden biri olarak tercih edilmiştir. Bu çalışmada kullanılan "RET" kelimesi aynı zamanda "Elvaloy" ürününü bünyesinde barındırmaktadır. Literatür taraması sonucunda, bulunan yayınlardan RET'lerin başka alanlarda kullanımını inceleyen yayınlar elenmiş ve sadece bitüm modifikasyonunun bulunduğu yayınlar seçilmiştir.

Seçilen yayınlar incelendiğinde bu çalışmalarda üç farklı şekilde RET kullanımına yer verildiği anlaşılmıştır. Bunlar: (1) bitüm modifikasyonunda RET'in etkisini belirlemek üzere sadece RET (veya RET ile birlikte polifosforik asit (PPA)) kullanımını içeren çalışmalar, (2) bitüm modifikasyonunda, içerisinde RET'lerin de yer aldığı çeşitli polimerlerin etkisini kıyaslamalı olarak inceleyen çalışmalar ve (3) RET ile modifiye edilmiş bitümlere başka katk1 malzemelerinin de ilave edilmesiyle hazırlanan kompozit modifiyeli bitümlerin incelendiği çalışmalar. Bu çalışmalardaki RETMB'lerden elde edilen özellikler bu çalışma kapsamında incelenmiştir. Hangi çalışmalarda kıyaslama yapıldığını, hangi çalışmalarda kompozit modifiyeli bitümlerin hazırlandığını okuyucuların daha iyi anlayabilmesi amacıyla bu çalışmada hazırlanan tablolarda bu konularla ilgili özel sütunlara yer verilmiştir.

RET'lerin bitüm modifikasyonunda kronolojik olarak kullanımı incelendiğinde çalışmaların başladığı ilk yıllarda sadece RETMB'lerin özelliklerinin incelendiği ve RETMB'ler ile diğer modifiyeli bitümlerin kıyaslandığı çalışmaların alana öncülük ettiği görülmektedir (Bagdat vd., 2015; Bhurke vd., 1997; Bulatovic vd., 2013, 2014b; Domingos ve Faxina, 2015a; Hafeez ve Kamal, 2009; Hesp vd., 2002; Keyf vd., 2007a; Michon vd., 1998; Pérez-Lepe vd., 2007; Polacco vd., 2004a; Selvavathi vd., 2002). Günümüze yaklaşıldığında ise kompozit modifikasyonda RET kullanımıyla ilgili yapılan çalışmaların sayısında bir artış meydana gelmiştir (Keyf, 2018; Singh vd., 2019a; Singh vd., 2019b; Singh vd., 2018; Xu vd., 2020; Xu vd., 2019). Bununla birlikte, güncel çalışmalarda önceki çalışmalara kıyasla farklı ve daha güncel deney yöntemleri ile sadece RET kullanımının incelendiği veya RET ile diğer katkı maddelerinin karşılaştırıldığg çalışmalar da görülmektedir (Ali vd., 2018; Almusawi vd., 2021a; Athira vd., 2020; Domingos vd., 2020; Geckil, 2019; Geckil ve Seloglu, 2018; Skronka vd., 2019). Bu durum dikkate alındığında, RET modifikasyonu ile ilgili kesin bir kronolojik yargıya varmanın mümkün olmadığı ancak RET'ler üzerine yapılan çalışmaların sayısının giderek arttığı anlaşılmaktadır.

$\mathrm{Bu}$ çalışmadaki alt başlıklar ve içerdikleri bilgiler şu şekildedir: 3. bölümde, RET'lerin kimyasal yapısı ile ilgili literatürden edinilen genel bilgiler verilmiş ve bu ürünlerin piyasada ve çalışmalarda bulunma şekillerine değinilmiştir. Modifiyeli bitüm karışımlarının hazırlanma koşulları PMB'lerin hem laboratuvar ortamında hem de uygulama esnasinda doğru şekilde üretilmesinde kritik bir rol oynamaktadır. Bu sebeple çalışmanın 4. bölümünde, RET ile ilgili yapılan çalışmalardan elde edilen, laboratuvar ortamında PMB karışımı hazırlama parametreleri incelenmiştir. 5. ve 6 . bölümlerde RET modifikasyonunun, sirasiyla bitümün fiziksel ve reolojik özelliklerine etkisi incelenmiştir. 7. bölümde RETMB'ler kullanılarak hazırlanan asfalt karışım numuneleri üzerinde yapılan çalışmalara yer verilmiştir. 8 . bölümde RET ile birlikte başka katkı maddelerinin kullanımı sonucunda elde edilen kompozit modifiyeli bitümleri içeren çalışmalar incelenmiştir. Son bölümde ise literatürden elde edilen bilgiler doğrultusunda, bitümün RET ile modifikasyonu hakkında yazarların genel yorumlarına yer verilmiştir.

\section{Reaktif etilen terpolimerler (RET'ler)}

RET'ler üç farklı monomerin birleşimi sonucunda oluşurlar: etilen, n-bütilakrilat ve glisidilmetakrilat (de Sá Araujo vd., 2013). Bitümün modifikasyonunda kullanılan diğer polimerlere kıyasla nispeten daha yeni bir ürün olan RET'lerin bitüm ile kimyasal bir bağ kurduğu varsayılmaktadır. Bu sebeple isimlerinde "reaktif" kelimesi bulunur. RET'lerin reaktiflikleri bünyelerinde, bitüm molekülleri ile bağ kurabilen fonksiyonel grupları barındırmalarından kaynaklanmaktadır (Polacco vd., 2004a). Keyf vd. (2007a), yaptıkları çalışmada RET'in asfaltenler içerisindeki karboksilik asit grupları ile reaksiyona girerek esterler oluşturduklarını belirtmişlerdir (Şekil 1). 


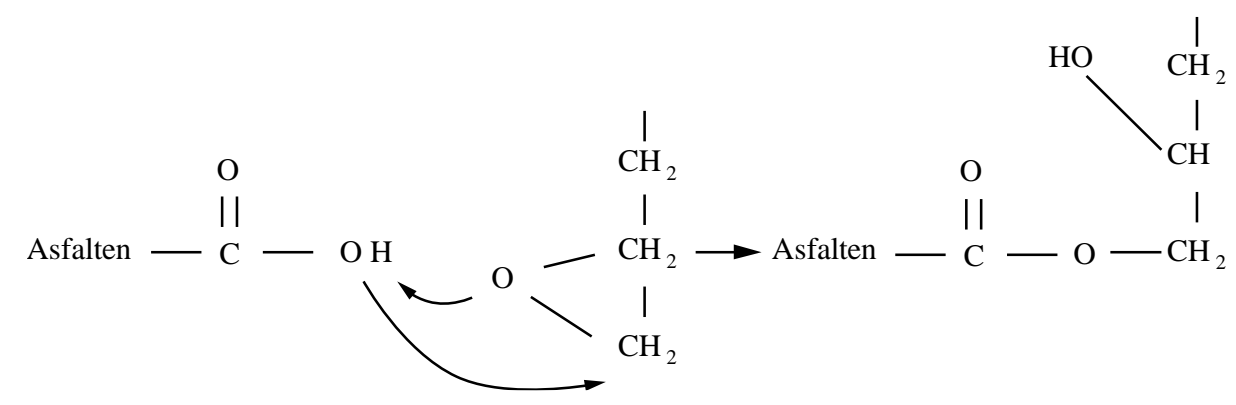

Şekil 1. RET ile asfalten içerisindeki karboksilik asit grupları arasındaki reaksiyon (Keyf vd., 2007a).

RET'ler bitüm modifikasyonunda kullanılmadan önce farklı endüstrilerde kendilerine yer bulmuşlardır. Örneğin, birçok çalışmada polimerik karışımların uyumlaştırıcıları olarak kullanılmışlardır (Chiono vd., 2003; Loyens ve Groeninckx, 2002; Minkova vd., 2002; Pazzagli ve Pracella, 2000; Polacco vd., 2004a). Buna ilaveten, çeliklerin korozyona karşı direncini arttırmak amaciyla kaplama malzemesi olarak kullanımları da mevcuttur (de Sá Araujo vd., 2013; Love vd., 2007). Farklı alanlardaki kullanımları devam etmekle birlikte, RET'lerin bitüm ile reaksiyona girdiğinin keşfedilmesiyle araştırmacılar tarafindan bitüm modifikasyonunda kullanımı incelenmeye başlanmıştır.

Bitüm modifikasyonunda hali hazırda yaygın olarak kullanılan elastomer ve plastomerlerin bitüm ile fiziksel bir etkileşimde bulunmaları yüksek sıcaklıklarda faz ayrışımına sebep olmaktadır. Faz ayrışımı ise bu polimerlerle modifiye edilen bitümlerin yüksek sıcakliklarda depolanmasını zorlaştırmakta ve modifiyeli bitümün özelliklerini kaybetmesiyle sonuçlanmaktadır. $\mathrm{Bu}$ problemlerin giderilmesi için araştırmacılar, sülfür vulkanizasyonu, antioksidanların ilave edilmesi, hidrofobik kil minerallerinin kullanımı ve işlevselleştirme gibi çeşitli yöntemler geliştirmişlerdir (Zhu vd., 2014). $\mathrm{Bu}$ yöntemlerin arasında reaktif polimerlerin bitüm modifikasyonunda kullanımı da yer almaktadır. RET'lerin bitüm ile fiziksel bir etkileşimden ziyade kimyasal bir etkileşim içerinde olmaları, polimer modifiyeli bitümdeki (PMB) faz ayrışımını engelleyerek depolama stabilitesi yüksek PMB üretimini mümkün k1lmaktadır (Gama vd., 2018).

Bitüm modifikasyonunda RET kullanımı avantajlara sahip olduğu gibi bazı dezavantajlara da sahiptir. Örneğin, modifikasyonda kullanılacak RET miktarının dikkatli bir şekilde seçilmesi gerekmektedir. Çünkü bitüme aşırı dozda RET ilavesi, çözünmez ve erimez bir bitüm jeli oluşumuna yol açacaktır. Bu olaya "jelleşme" adı verilir. $\mathrm{Bu}$ riskten kaçınılması için bazı araştırmacılar yaptıkları çalışmalarda bitüm modifikasyonunda kullanılacak RET oranının \%1.5-2.5 aralığında olması gerektiğini belirtmişlerdir (Domingos ve Faxina, 2015b; Polacco vd., 2004b). Fakat modifikasyonda bir üst sınırın bulunması, bitümün özelliklerinde yapılacak iyileştirmelerin ancak belirli bir seviyeye kadar ulaşabileceği anlamına gelmektedir. Buna ilaveten, RET ile bitüm arasındaki reaksiyonun tamamlanması zaman almaktadır. Bu reaksiyonun tamamlanması için belirli bir süre ( 24 veya 48 saat) $160-180^{\circ} \mathrm{C}$ sicaklıkta modifiyeli bitüme kür uygulanması tavsiye edilmektedir (Polacco vd., 2004a). Araştırmacılar bitüm ile RET arasındaki tepkimenin hızlanması ve kür süresinin kısaltılması için RET ile birlikte katalizör olarak polifosforik asit (PPA) kullanımını tavsiye etmişlerdir (Singh vd., 2019a). PPA hali hazırda yüksek bitümün yüksek sıcaklık performansını arttıran bir katk1 maddesi olarak ayrıca kullanılmaktadır ( $\mathrm{Li}$ vd., 2011). RET ile geliştirilen yükseklik sıcaklık performansına ayrıca PPA da katkı sağladığı için ilave edilen RET miktarının azaltılmasını mümkün kılarak jelleşme riskinden kaçınılmasını mümkün kılmıştır (Gama vd., 2018; Singh vd., 2019a).

Günümüzde RET'ler, bitüm modifikasyonunda kullanılmak amacıyla farklı firmaların ürettiği ticari ürünler olarak temin edilebilmektedirler. Dow Chemicals firmasının ürettiği Elvaloy (Dow, 2021a) ve Arkema firmasının ürettiği Lotader (Lotader, 2021), literatürde yaygın olarak kullanılan RET'lerdir. Bununla birlikte, bitüm modifikasyonu ile ilgili yapılan çalışmalar dikkate alındığında Elvaloy'un diğerine kıyasla çok daha popüler olduğu görülmektedir. Bu sebeple, bu çalışma Elvaloy RET ile ilgili yapılan çalışmalar dikkate alınarak hazırlanmıştır. Ayrıca, Elvaloy markası altında birden çok model bulunmaktadır. Bunlar, isimlerine ilave edilen numaralar ve harfler ile birbirlerinden ayrılmaktadır. Örneğin farklı çalışmalarda; Elvaloy AM (Bulatovic vd., 2013), Elvaloy 4170 (Domingos ve Faxina, 2015b; Geckil ve Seloglu, 2018), Elvaloy AC (Ali vd., 2018), Elvaloy RE (Pérez-Lepe vd., 2007), Elvaloy 5160 
(Geckil, 2019) gibi farklı modellerdeki RET'lere rastlamak mümkündür. Bu ürünler arasındaki fark içerdikleri bütil akrilat ve glisidil metilakrilat oranlarıdır. Örneğin; Elvaloy AM ağırlığınca \%28 bütil akrilat ve $\% 5.3$ glisidil metilakrilat içeriyorken Elvaloy 4170 ağrılınca $\% 20$ bütil akrilat ve \%9 glisidil metilakrilat içermektedir (Bulatovic vd., 2013; Polacco vd., 2004a). Bu oranlar doğrultusunda RET'in bitüm üzerindeki etkisi değişiklik göstermektedir. Her ne kadar böyle bir etki söz konusu olsa da bazı çalışmalarda (Bricker ve Hesp, 2013; Li vd., 2011; Miknis ve Thomas, 2008; Selvavathi vd., 2002; Singh vd., 2017) kullanılan RET türü bulunamamıştır. $\mathrm{Bu}$ çalışmada, incelemeye tabi tutulan yayınlarda kullanılan RET türü belirtilmeye çalışılmıştır.

\section{RETMB'lerin hazırlanmasında kullanılan karıştırma parametreleri}

PMB'ler hazırlanırken stabil bir modifikasyonun sağlanabilmesi için bitüm ile polimerin karıştırılması esnasında tercih edilen karıştırma parametreleri ve bitüm ile polimer arasındaki uyumluluk kritik bir öneme sahiptir (Perez-Lepe vd., 2003). Bitüm ile reaksiyona girebilen RET'lerin uyumluluk açısından herhangi bir problemi yoktur. Bu hususta, Topal (2010) yaptığ1 çalışmada RETMB'lerin morfolojisini floresan mikroskopisi görüntüleriyle incelemiş ve RET'in bitüm ile olan uyumluluğu veya çözünürlük kabiliyeti sayesinde bitüm ile RET arasında herhangi bir faz ayrışımının gözlemlenmediğini ifade etmiştir. Benzer şekilde (Geckil, 2019), yaptı̆g taramalı elektron mikroskopisi kullanarak incelemiş ve RETMB'nin homojen bir yapıda olduğunu belirtmiştir. Bununla birlikte RET ve bitüm arasındaki morfolojik uyumluluğun yanı sira, RETMB'lerin hazırlanması sirasinda tercih edilen karıştırma koşullarının da PMB'nin performans1 üzerinde önemli bir etkisi olacağı aşikârdır. Karışım hazırlama parametreleri; bitüme ilave edilecek polimer miktarı, karıştırıcı türü, karıştırma süresi, hızı ve sicaklığ 1 olarak sayılabilir. Bununla birlikte, RETMB'lerde eğer uygulandıysa kür süresi ve sıcaklığı da önem taşımaktadır. Eğer hazırlanan RETMB yetersiz süre kür ortamında tutulursa RET ile bitüm arasındaki reaksiyon tamamlanmayacak ve modifiyeli bitümden istenilen verim alınamayacaktır. Bununla birlikte yazarlar tarafindan, uzun süre kür koşulunda bekletilen bitümün ise yüksek sıcaklık etkisi altında erken yaşlanmaya maruz kalacağı düşünülmektedir. Tüm $\mathrm{bu}$ parametrelerin yanında, modifiye edilen saf bitümün özelliklerinin PMB üzerinde çok büyük bir etkisinin olduğu unutulmamalıdır.

Üretici firmanın 2020 yılında internet sitesi üzerinden yayınladığ 1 tanıtım videosu dikkate alındığında RETMB'lerin hazırlanması için gerekli koşullar şöyledir (Dow, 2021b): karıştırma sicaklığ $1,165-175{ }^{\circ} \mathrm{C}$; RET ilave miktarı, \%2; karıştırma süresi, 2 saat; PPA ilave miktarı, \%0.4; PPA ilaveli ek karıştırma süresi, 1 saat. Bunlara ek olarak, tüm bu karıştırma işlemi düşük kesmeli karıştırıcıda (dört kollu mekanik karıştırıcıda) gerçekleştirilmiştir. Ancak, karıştırma hızının kaç dev/dk olduğu ile ilgili bir bilgi bu tanıtım içerisinde bulunmamaktadır. $\mathrm{Bu}$ tanıtım, laboratuvar ortamında RET'ler ile çalışacak araştırmacılar için faydalı bilgiler içermektedir.

Literatürde RET'in kullanıldığı çalışmalar incelendiğinde ise firmanın tavsiyelerinden çok farklı koşullar takip edilerek RETMB'lerin hazırlandığ 1 fark edilmiştir. Bu doğrultuda, her bir çalışmada tercih edilen karıştırma parametreleri Tablo 1.'de verilmiştir.

Tablo 1 incelendiğinde RET ile genellikle düşük penetrasyonlu bitümlerin modifiye edildiği görülmektedir. Bununla birlikte, bazı çalışmalarda yumuşak kıvamlı bitümler de kullanılmıştır. Kullanılan RET türünün bazı çalışmalarda belirtildiği, bazılarında sadece RET olarak ifade edildiği görülmektedir. Saf bitüme ilave edilecek RET miktarı ise çalışmaların birçoğunda birbirlerine paralel olarak bitümün ağırlığınca \%12 aralığında tercih edilmiştir. Buna ilaveten, bazı çalışmalarda PPA kullanılmış ve ilave edilecek PPA miktarı genellikle bitümün ağırlığınca \%0.20.4 aralığında seçilmiştir.

Literatürdeki çalışmalar, Tablo 1'de görüldüğü üzere, karıştırma koşullarında birbirinden büyük farklılıklar göstermektedirler. Her ne kadar üretici firma laboratuvar ortamında RETMB hazırlamak için yüksek kesmeli karıştırıcının gerekli olmadığını belirtmiş olsa da (Dow, 2021b), yapılan akademik çalışmaların önemli bir kısmında bu tür karıştırıcılar vasıtası ile RETMB'lerin hazırlandığı görülmektedir. Karıştırıcı seçimi büyük önem taşımakla birlikte, Xu vd. (2019) yaptıkları çalışmada, farklı türdeki karıştırıcıları farklı karıştırma veya kesme hızlarında kullanmanın RET/PUP kompozit modifiyeli bitümler üzerindeki etkilerini incelemişlerdir. Yaptıkları çalışmanın sonuçlarına göre kesmeli karıştırma işlemi ile RET/PUP kompozit modifiyeli bitümlerden daha iyi bir performans elde edildiğ görülmektedir. Fakat bu çalışmada, sadece RET ile 
modifiye edilen bitüm üzerinde kesmeli karıştırıcının etkisi incelenmediği için bu konuda halen bir bilgi eksikliği mevcuttur. Bu nedenle, üretici firmanın tavsiyesi doğrultusunda mekanik karıştırıcı kullanılarak yapılacak çalışmaların daha makul sonuçlar vereceği düşünülmektedir.

Tablo 1. Laboratuvar ortamında RETMB hazırlama koşulları.

\begin{tabular}{|c|c|c|c|c|c|c|c|c|c|c|c|c|c|}
\hline \multirow[t]{2}{*}{ No } & \multirow{2}{*}{$\begin{array}{l}\text { Saf } \\
\text { Bitüm }\end{array}$} & \multirow{2}{*}{$\begin{array}{l}\text { RET } \\
\text { Türü }\end{array}$} & \multirow{2}{*}{$\begin{array}{l}\text { RET } \\
(\%)\end{array}$} & \multirow{2}{*}{$\begin{array}{l}\text { PPA } \\
(\%)\end{array}$} & \multirow{2}{*}{$\begin{array}{l}\text { RBK } \\
\text { KM* }\end{array}$} & \multirow{2}{*}{$\underset{* *}{\mathbf{K K K M}}$} & \multicolumn{4}{|c|}{ Karıştırma Parametreleri } & \multicolumn{2}{|c|}{ Kür Koşulları } & \multirow[t]{2}{*}{ Referans } \\
\hline & & & & & & & $\begin{array}{l}\text { Karıştırıc1 } \\
\text { Türü }\end{array}$ & $\begin{array}{l}\mathrm{H} 1 \mathrm{z} \\
(\mathrm{rpm})\end{array}$ & $\begin{array}{l}\text { Sic. } \\
\left({ }^{\circ} \mathrm{C}\right)\end{array}$ & Süre & $\begin{array}{l}\text { Sic. } \\
\left({ }^{\circ} \mathrm{C}\right)\end{array}$ & Süre & \\
\hline 1 & $\begin{array}{l}\mathrm{AC} \\
60 / 70 \\
\mathrm{AC} \\
80 / 100\end{array}$ & RET & $\begin{array}{l}1.5 \\
2,2.5\end{array}$ & - & - & $\mathrm{CR}$ & $\begin{array}{l}\text { Mekanik } \\
\text { karıştırıcı }\end{array}$ & $1 / 2 \mathrm{HP}$ & 180 & $2 \mathrm{~s}$ & 180 & $1 \mathrm{~s}$ & $\begin{array}{l}\text { (Selvavathi vd., } \\
\text { 2002) }\end{array}$ \\
\hline 2 & $\begin{array}{l}\mathrm{AC} \\
70 / 100\end{array}$ & $\begin{array}{l}\text { Elvaloy } \\
\text { AM; } \\
\text { Elvaloy } \\
4170\end{array}$ & $\begin{array}{l}1, \\
1.5 \\
1.75 \\
2,2.5\end{array}$ & - & - & - & $\begin{array}{l}\text { Yüksek } \\
\text { kesmeli } \\
\text { karıştırıcı }\end{array}$ & 3000 & 180 & - & 180 & $\begin{array}{l}0,24,48 \text { ve } \\
72 \mathrm{~s}\end{array}$ & (Polacco vd., 2004a) \\
\hline 3 & $\begin{array}{l}\mathrm{AC} \\
70 / 100\end{array}$ & $\begin{array}{l}\text { Elvaloy } \\
\text { AM }\end{array}$ & $\begin{array}{l}1.75 \\
4\end{array}$ & - & - & $\begin{array}{l}\text { SBS, } \\
\text { EVA }\end{array}$ & $\begin{array}{l}\text { Yüksek } \\
\text { kesmeli } \\
\text { karıştırıcı }\end{array}$ & - & 180 & $\begin{array}{l}15 \\
\mathrm{dk}\end{array}$ & 180 & $\begin{array}{l}0,24,48 \mathrm{ve} \\
72 \mathrm{~s}\end{array}$ & (Polacco vd., 2004b) \\
\hline 4 & $\begin{array}{l}\mathrm{AC} \\
60 / 70\end{array}$ & RETP & $\begin{array}{l}0.4 \\
0.6 \\
0.8 \\
1,1.2\end{array}$ & 0.2 & ETP & - & $\begin{array}{l}\text { Mekanik } \\
\text { karıştırıcı }\end{array}$ & 90 & 190 & $6 \mathrm{~s}$ & - & - & $\begin{array}{l}\text { (Keyf vd., 2007a, } \\
2007 b)\end{array}$ \\
\hline 5 & $\begin{array}{l}\mathrm{AC} \\
60 / 70\end{array}$ & $\begin{array}{l}\text { Elvaloy } \\
\text { RE }\end{array}$ & 2 & - & - & $\begin{array}{l}\text { SBS, } \\
\text { HDPE, } \\
\text { LDPE, } \\
\text { EPDM }\end{array}$ & $\begin{array}{l}\text { Özel } \\
\text { karıştırıcı }\end{array}$ & 8200 & 180 & - & 180 & $24 \mathrm{~s}$ & $\begin{array}{l}\text { (Pérez-Lepe vd., } \\
\text { 2007) }\end{array}$ \\
\hline 6 & $\begin{array}{l}\text { SHRP } \\
\text { bitümü }\end{array}$ & Elvaloy & 3 & 0.2 & - & PPA & $\begin{array}{l}\text { Yüksek } \\
\text { kesmeli } \\
\text { karıştırıcı }\end{array}$ & 3000 & 140 & $\begin{array}{l}30 \\
\mathrm{dk}\end{array}$ & - & - & $\begin{array}{l}\text { (Miknis ve Thomas, } \\
\text { 2008) }\end{array}$ \\
\hline 7 & $\begin{array}{l}\mathrm{AC} \\
60 / 70\end{array}$ & $\begin{array}{l}\text { Elvaloy } \\
4170\end{array}$ & $\begin{array}{l}1 \\
1.5 \\
1.75 \\
2\end{array}$ & 0.2 & - & - & - & - & 190 & $3 \mathrm{~s}$ & - & - & $\begin{array}{l}\text { (Hafeez ve Kamal, } \\
\text { 2009) }\end{array}$ \\
\hline 8 & $\begin{array}{l}\mathrm{AC} \\
50 / 70\end{array}$ & $\begin{array}{l}\text { Elvaloy } \\
4170\end{array}$ & 2 & - & SBS & - & $\begin{array}{l}\text { Mekanik } \\
\text { karıştırıcı }\end{array}$ & 90 & 195 & $6 \mathrm{~s}$ & - & - & (Keyf, 2010) \\
\hline 9 & $\begin{array}{l}\mathrm{AC} \\
50 / 70\end{array}$ & $\begin{array}{l}\text { Elvaloy } \\
4170 ; \\
\text { Elvaloy } \\
3427\end{array}$ & $\begin{array}{l}0.5 \\
1, \\
1.5 \\
1.75 \\
2-6\end{array}$ & - & - & Evatane & $\begin{array}{l}\text { Yüksek } \\
\text { kesmeli } \\
\text { karıştırıcı }\end{array}$ & $\begin{array}{l}1100- \\
1250\end{array}$ & $\begin{array}{l}180- \\
185\end{array}$ & $2 \mathrm{~s}$ & - & - & (Topal, 2010) \\
\hline 10 & $\begin{array}{l}\mathrm{AC} \\
70 / 100\end{array}$ & $\begin{array}{l}\text { Elvaloy } \\
\text { AM, } \\
\text { Elvaloy } \\
4170\end{array}$ & $\begin{array}{l}1.6 \\
1.9\end{array}$ & - & - & $\begin{array}{l}\text { SBS, } \\
\text { EVA }\end{array}$ & $\begin{array}{l}\text { Yüksek } \\
\text { kesmeli } \\
\text { karıştırma }\end{array}$ & - & $\begin{array}{l}180- \\
185\end{array}$ & $4 \mathrm{~s}$ & 180 & $24 \mathrm{~s}$ & $\begin{array}{l}\text { (Bulatovic vd., } \\
\text { 2014a; Bulatovic vd., } \\
\text { 2012, 2013, 2014b) }\end{array}$ \\
\hline 11 & VG 30 & $\begin{array}{l}\text { Elvaloy } \\
4170\end{array}$ & $\begin{array}{l}1.5, \\
1.8,2\end{array}$ & - & - & - & $\begin{array}{l}\text { Mekanik } \\
\text { karıştırıcı }\end{array}$ & 1550 & 180 & $\begin{array}{r}90 \\
\mathrm{dk}\end{array}$ & - & - & $\begin{array}{l}\text { (Vachhani ve Mishra, } \\
\text { 2014) }\end{array}$ \\
\hline 12 & $\begin{array}{l}\text { AC } \\
90 / 130\end{array}$ & $\begin{array}{l}\text { Elvaloy } \\
4170\end{array}$ & 1.4 & - & - & - & $\begin{array}{l}\text { Mekanik } \\
\text { karıştırıcı }\end{array}$ & 200 & 180 & $2 \mathrm{~s}$ & 180 & $10 \mathrm{dk}$ & (Bagdat vd., 2015) \\
\hline 13 & $\begin{array}{l}\mathrm{AC} \\
50 / 70\end{array}$ & $\begin{array}{l}\text { Elvaloy } \\
4170\end{array}$ & 1.3 & 0.3 & - & $\begin{array}{l}\text { PPA, } \\
\text { SBS, PE }\end{array}$ & $\begin{array}{l}\text { Mekanik } \\
\text { karıştırıcı }\end{array}$ & 300 & 190 & $2 \mathrm{~s}$ & - & - & $\begin{array}{l}\text { (Domingos ve } \\
\text { Faxina, 2015a, } \\
\text { 2015b) }\end{array}$ \\
\hline 14 & $\begin{array}{l}\mathrm{AC} \\
50 / 70\end{array}$ & $\begin{array}{l}\text { Elvaloy } \\
4170\end{array}$ & 0.6 & 0.2 & - & $\begin{array}{l}\text { PPA, } \\
\text { SBS }\end{array}$ & $\begin{array}{l}\text { Yüksek } \\
\text { kesmeli } \\
\text { karıştırıcı }\end{array}$ & - & 180 & - & - & - & $\begin{array}{l}\text { (Hampl vd., 2015; } \\
\text { Jasso vd., 2015) }\end{array}$ \\
\hline 15 & $\begin{array}{l}\mathrm{AC} \\
50 / 70\end{array}$ & $\begin{array}{l}\text { Elvaloy } \\
4170\end{array}$ & 1 & 0.2 & $\begin{array}{l}\text { SBS, } \\
\text { EVA }\end{array}$ & - & $\begin{array}{l}\text { Mekanik } \\
\text { karıştırıcı }\end{array}$ & 120 & 200 & $2-7 \mathrm{~s}$ & - & - & (Keyf, 2015) \\
\hline 16 & $\begin{array}{l}\mathrm{AC} \\
60 / 70\end{array}$ & $\begin{array}{l}\text { Elvaloy } \\
\text { RET }\end{array}$ & 1.35 & $1.4 \mathrm{~g}$ & & - & $\begin{array}{l}\text { Mekanik } \\
\text { karıştırıcı }\end{array}$ & 120 & 165 & $\begin{array}{l}90 \\
\mathrm{dk}\end{array}$ & - & $2 \mathrm{~s}$ & (Javid, 2016) \\
\hline
\end{tabular}


Tablo 1. Devami.

\begin{tabular}{|c|c|c|c|c|c|c|c|c|c|c|c|c|c|}
\hline \multirow{2}{*}{\multicolumn{2}{|c|}{$\begin{array}{l}\text { No Saf } \\
\text { Bitüm }\end{array}$}} & \multirow{2}{*}{$\begin{array}{l}\text { RET } \\
\text { Türü }\end{array}$} & \multirow{2}{*}{$\begin{array}{l}\text { RET } \\
(\%)\end{array}$} & \multirow{2}{*}{$\begin{array}{l}\text { PPA } \\
(\%)\end{array}$} & \multirow{2}{*}{$\begin{array}{l}\text { RBKKM } \\
*\end{array}$} & \multirow{2}{*}{$\underset{* *}{\mathbf{K K K M}}$} & \multicolumn{4}{|c|}{ Karıştırma Parametreleri } & \multicolumn{2}{|c|}{ Kür Koşulları } & \multirow[t]{2}{*}{ Referans } \\
\hline & & & & & & & $\begin{array}{l}\text { Karıştırıcı } \\
\text { Türü }\end{array}$ & $\begin{array}{l}\mathrm{H} 1 \mathrm{z} \\
(\mathrm{rpm})\end{array}$ & $\begin{array}{l}\text { Sic. } \\
\left({ }^{\circ} \mathrm{C}\right)\end{array}$ & Süre & $\begin{array}{l}\text { Sic. } \\
\left({ }^{\circ} \mathrm{C}\right)\end{array}$ & Süre & \\
\hline 17 & $\begin{array}{l}\mathrm{AC} \\
50 / 70\end{array}$ & $\begin{array}{l}\text { Elvaloy } \\
4170\end{array}$ & 1.6 & 0.5 & - & $\begin{array}{l}\text { SBS, } \\
\text { SBR, } \\
\text { PPA }\end{array}$ & $\begin{array}{l}\text { Mekanik } \\
\text { karıştırıcı }\end{array}$ & 300 & 190 & $2 \mathrm{~s}$ & - & - & $\begin{array}{l}\text { (Domingos vd., 2020; } \\
\text { Domingos vd., 2017) }\end{array}$ \\
\hline 18 & $\begin{array}{l}\mathrm{AC} \\
60 / 70\end{array}$ & $\begin{array}{l}\text { Elvaloy } \\
4170\end{array}$ & $\begin{array}{l}1,2,3, \\
4\end{array}$ & & - & - & $\begin{array}{l}\text { Yüksek } \\
\text { kesmeli } \\
\text { karıştırıcı }\end{array}$ & 1000 & 180 & - & - & - & (Irfan vd., 2017) \\
\hline 19 & VG 30 & Elvaloy & 1.6 & 0.3 & $\begin{array}{l}\text { Sasobit, } \\
\text { Advera, } \\
\text { Evotherm, } \\
\text { Sönmüş } \\
\text { Kireç }\end{array}$ & - & $\begin{array}{l}\text { Yüksek } \\
\text { kesmeli } \\
\text { karıştırıcı }\end{array}$ & 1000 & 175 & $90 \mathrm{dk}$ & - & - & $\begin{array}{l}\text { (Singh vd., 2019a; } \\
\text { Singh vd., 2017, } \\
\text { 2019b; Singh vd., } \\
\text { 2018) }\end{array}$ \\
\hline 20 & $\begin{array}{l}\mathrm{AC} \\
40 / 50, \\
\mathrm{AC} \\
60 / 80, \\
\mathrm{AC} \\
80 / 100\end{array}$ & $\begin{array}{l}\text { Elvaloy } \\
\text { RET; } \\
\text { Elvaloy } \\
\text { AC }\end{array}$ & $\begin{array}{l}1.35 \\
1.7,2 \\
2.5 \\
3.5 \\
4.5\end{array}$ & 0.2 & - & - & - & - & 165 & $2 \mathrm{~s}$ & 165 & $90 \mathrm{dk}$ & (Ali vd., 2018) \\
\hline 21 & $\begin{array}{l}P G \\
67-22\end{array}$ & $\begin{array}{l}\text { EMA- } \\
\text { GMA }\end{array}$ & 1.8 & $\begin{array}{l}0.15 \\
-0.3\end{array}$ & HDPE & $\begin{array}{l}\text { SBS, } \\
\text { HDPE, } \\
\text { PPA }\end{array}$ & $\begin{array}{l}\text { Mekanik } \\
\text { karıştırıcı }\end{array}$ & 2500 & 165 & $60 \mathrm{dk}$ & 160 & $12 \mathrm{~s}$ & (Gama vd., 2018) \\
\hline 22 & $\begin{array}{l}\mathrm{AC} \\
100 / \\
150\end{array}$ & $\begin{array}{l}\text { Elvaloy } \\
4170\end{array}$ & $\begin{array}{l}0.5, \\
0.75,1\end{array}$ & 0.3 & - & - & $\begin{array}{l}\text { Mekanik } \\
\text { karıştırıcı }\end{array}$ & 500 & 185 & $2 \mathrm{~s}$ & 185 & $90 \mathrm{dk}$ & $\begin{array}{l}\text { (Geckil ve Seloglu, } \\
\text { 2018) }\end{array}$ \\
\hline 23 & $\begin{array}{l}\mathrm{AC} \\
50 / 70\end{array}$ & $\begin{array}{l}\text { Elvaloy } \\
\text { RET }\end{array}$ & $\begin{array}{l}0.5,1 \\
1.5,2 \\
2.5\end{array}$ & 0.2 & SBS, EVA & - & $\begin{array}{l}\text { Mekanik } \\
\text { karıştırıcı }\end{array}$ & 120 & 190 & $2-7 \mathrm{~s}$ & - & - & (Keyf, 2018) \\
\hline 24 & $\begin{array}{l}\mathrm{AC} \\
50 / 70\end{array}$ & $\begin{array}{l}\text { Elvaloy } \\
4170\end{array}$ & 1.5 & - & - & $\begin{array}{l}\text { SBS, } \\
\text { Sasobit, } \\
\text { Rediset }\end{array}$ & $\begin{array}{l}\text { Mekanik } \\
\text { karıştırıcı }\end{array}$ & 200 & 185 & $2 \mathrm{~s}$ & 190 & $24 \mathrm{~s}$ & $\begin{array}{l}\text { (Almusawi vd., 2021a, } \\
\text { 2021b; Almusawi vd., } \\
\text { 2019) }\end{array}$ \\
\hline 25 & $\begin{array}{l}\mathrm{AC} \\
160 / \\
220\end{array}$ & $\begin{array}{l}\text { Elvaloy } \\
5160\end{array}$ & $\begin{array}{l}0.4 \\
0.8 \\
1.2\end{array}$ & 0.3 & - & - & $\begin{array}{l}\text { Mekanik } \\
\text { karıştırıcı }\end{array}$ & 500 & 185 & $2 \mathrm{~s}$ & 185 & $90 \mathrm{dk}$ & (Geckil, 2019) \\
\hline 26 & $\begin{array}{l}\mathrm{AC} \\
50 / 70\end{array}$ & $\begin{array}{l}\text { Elvaloy } \\
\text { RET }\end{array}$ & $\begin{array}{l}1, \\
1.25, \\
1.5, \\
1.75,2\end{array}$ & 0.2 & $\begin{array}{l}\text { PUP; } \\
\text { GWR }\end{array}$ & - & $\begin{array}{l}\text { Mekanik } \\
\text { karıştırıcı / } \\
\text { Yüksek } \\
\text { kesmeli } \\
\text { karıştırıcı }\end{array}$ & $\begin{array}{l}1000- \\
6000\end{array}$ & $\begin{array}{l}170- \\
180\end{array}$ & $\begin{array}{l}0.5- \\
2.5 \mathrm{~s}\end{array}$ & - & - & $\begin{array}{l}\text { (Xu vd., 2020; Xu vd., } \\
\text { 2019) }\end{array}$ \\
\hline 27 & $\begin{array}{l}\mathrm{AC} \\
60 / 70\end{array}$ & $\begin{array}{l}\text { Elvaloy } \\
4170\end{array}$ & 0.25 & 0.3 & - & $\begin{array}{l}\text { Sülfür, } \\
\text { MPC, } \\
\text { CNP, } \\
\text { GNP, } \\
\text { CNT }\end{array}$ & $\begin{array}{l}\text { Mekanik } \\
\text { karıştırıcı }\end{array}$ & 500 & 185 & $2 \mathrm{~s}$ & 185 & $90 \mathrm{dk}$ & (Alam vd., 2020) \\
\hline
\end{tabular}

Kısaltmalar: Sıcaklık, Sıc.; Yüksek yoğunluklu polietilen, HDPE; düşük yoğunluklu polietilen, LDPE; etilen-propilen-dien terpolimer, EPDM; polietilen, PE; etilen terpolimeri, ETP; poliüretan prepolimeri, PUP; öğütülmüş atık kauçuk, GWR; metan fosfor bileşiği, MPC, grafen nanolevhacıklar, GNP; karbon nanotüpler, CNT; karbon nanolevhacıklar.

*RBKKM: RET ile birlikte kullanılan katkı malzemeleri

**KKKM: Kıyaslamada kullanılan katk1 malzemeleri

Bir diğer önemli karıştırma koşulu olan sıcaklık ile ilgili olarak Tablo 1 incelendiğinde, yapılan çalışmalarda genellikle $175-185{ }^{\circ} \mathrm{C}$ aralığında bir karıştırma sıcaklığının seçildiği görülmektedir. Karıştırma süresine bakıldığında ise çalışmaların büyük bir kısmında 2 saatlik karıştırma süresinin tercih edildiği anlaşılmaktadır. Bunlara ilaveten, karıştırma işleminden sonra kür uygulanıp uygulanmaması değişkenlik gösteren bir durumdur. Bazı çalışmalarda yüksek sıcaklıklarda birkaç gün gibi oldukça uzun süreli kürleme koşulları tercih edilmiş olup bu sürelerin bitümün yaşlanması üzerindeki etkisi merak uyandırmaktadır. Bununla birlikte, bazı 
çalışmalarda ise kısa süreli kür yapılmış veya kür işlemi uygulanmamıştır. Tablo 1 dikkatli incelendiğinde genellikle PPA ilavesiz karışımların küre tabi tutulduğu, PPA ilaveli karışımlara ise kısa süreli kür uygulandığı veya kür uygulanmadığı fark edilmiştir. Bu durum, PPA'nın yaygın bir şekilde RETMB'lerde katalizör olarak kullanıldığını kanıtlar niteliktedir.

\section{RET modifikasyonun saf bitümün fiziksel özelliklerine etkisi}

Bitümlerin fiziksel özellikleri penetrasyon ve yumuşama noktası gibi geleneksel deneyler ile uzun yillardan beri incelenmektedir. Bu deneyler, bitümlerin kıvamının sert veya yumuşak olması hakkında bilgi vermektedirler. Penetrasyon değerinde meydana gelen düşüş ve yumuşama noktasında meydana gelen artış bitümün kıvamının sertleştiğini gösterir.

Literatürde RETMB'lerle ilgili çalışmalardan geleneksel deneylere yer verilenler seçilmiş ve Tablo 2'de liste halinde verilmiştir. Bu tabloda, çalışmalarda kullanılan saf bitüm sınıfı, RET türü ve miktarı dikkate alınarak seçilen çalıșmalar birbirlerinden ayrılmıştır. Ardından, her bir çalışma için saf bitüme (veya kontrol bitümüne) RET ilavesiyle; penetrasyon, yumuşama noktası ve düktilite değerlerinde meydana gelen azalma veya artma ok işaretleriyle ifade edilmiştir. Son olarak, çalışmalardaki bazı bulgular kısaca belirtilmiştir.

Tablo 2. RET modifikasyonunun saf bitümün fiziksel özelliklerine etkileri.

\begin{tabular}{|c|c|c|c|c|c|c|c|c|c|}
\hline \multirow[t]{2}{*}{ No } & \multirow{2}{*}{$\begin{array}{l}\text { Saf } \\
\text { Bitüm }\end{array}$} & \multirow{2}{*}{$\begin{array}{l}\text { RET } \\
\text { Türü }\end{array}$} & \multirow{2}{*}{$\begin{array}{l}\text { RET } \\
(\%)\end{array}$} & \multirow{2}{*}{$\begin{array}{l}\text { PPA } \\
(\%)\end{array}$} & \multicolumn{3}{|c|}{ RET etkisi } & \multirow[t]{2}{*}{ Bulgular } & \multirow[t]{2}{*}{ Referans } \\
\hline & & & & & Pen. & Y.N. & Dük. & & \\
\hline 1 & $\begin{array}{l}\mathrm{AC} \\
60 / 70 \\
\mathrm{AC} \\
80 / 100\end{array}$ & RET & $\begin{array}{l}1.5 \\
2,2.5\end{array}$ & - & $\downarrow$ & & - & $\begin{array}{l}\text { Modifiyeli bitümün yumuşama noktasında önemli } \\
\text { bir artışın meydana geldiğini belirtmişlerdir. } \\
\text { Ayrıca, RET modifikasyonunun BSK } \\
\text { numunelerinin Marshall stabilitelerini arttırdığını } \\
\text { belirtmişlerdir. }\end{array}$ & $\begin{array}{l}\text { (Selvavathi } \\
\text { vd., 2002) }\end{array}$ \\
\hline 2 & $\begin{array}{l}\mathrm{AC} \\
60 / 70\end{array}$ & RETP & $\begin{array}{l}0.4 \\
0.6 \\
0.8 \\
1,1.2\end{array}$ & 0.2 & $\downarrow$ & 个 & $\downarrow$ & $\begin{array}{l}\text { Bu çalışmada sabit oranda }(\% 2.4) \text { ETP ile } \\
\text { modifiyeli bitüme farklı oranlarda RET katmıştır. } \\
\text { Ayrıca, karıştırma süresinin etkisi de } \\
\text { incelenmiştir. Karıştırma süresi ve RET miktarı } \\
\text { arttıkça yumuşama noktası artmış penetrasyon } \\
\text { değeri azalmıştır. }\end{array}$ & $\begin{array}{l}\text { (Keyf vd., } \\
2007 b)\end{array}$ \\
\hline 3 & $\begin{array}{l}\mathrm{AC} \\
60 / 70\end{array}$ & $\begin{array}{l}\text { Elvaloy } \\
4170\end{array}$ & $\begin{array}{l}1 \\
1.5 \\
1.75 \\
2\end{array}$ & 0.2 & - & $\uparrow$ & $\downarrow$ & $\begin{array}{l}\text { Çalışmada reolojik özellikler yorumlanmıştır. } \\
\text { Fiziksel özellikler sadece bir tabloda verilmiştir. }\end{array}$ & $\begin{array}{l}\text { (Hafeez ve } \\
\text { Kamal, 2009) }\end{array}$ \\
\hline 4 & $\begin{array}{l}\mathrm{AC} \\
50 / 70\end{array}$ & $\begin{array}{l}\text { Elvaloy } \\
4170 ; \\
\text { Elvaloy } \\
3427\end{array}$ & $\begin{array}{l}0.5 \\
1 \\
1.5 \\
1.75 \\
2-6\end{array}$ & - & $\downarrow$ & $\uparrow$ & - & $\begin{array}{l}\text { Bu çalışmada farklı polimerlerle modifiye edilen } \\
\text { bitümlerin kıyaslanmasında geleneksel bitüm } \\
\text { deneylerinin belirleyici olduğu ifade edilmiştir. } \\
\text { Ayrıca, Elvaloy } 4170 \text { ile modifiye edilen bitümün } \\
\text { diğer polimerlere kıyasla saf bitüm üzerinde daha } \\
\text { fazla iyileştirme sağladığı belirlenmiştir. }\end{array}$ & (Topal, 2010) \\
\hline 5 & $\begin{array}{l}\mathrm{AC} \\
50 / 70 \\
\mathrm{AC} \\
70 / 100\end{array}$ & $\begin{array}{l}\text { Elvaloy } \\
\text { AM, } \\
\text { Elvaloy } \\
4170\end{array}$ & $\begin{array}{l}1.6, \\
1.9\end{array}$ & - & $\downarrow$ & & - & $\begin{array}{l}\text { Elvaloy ile modifiye edilen saf bitümün } \\
\text { penetrasyon değerinde çok fazla bir düşüş } \\
\text { meydana gelmeden yumuşama noktası değerinin } \\
\text { arttığını belirlemişlerdir. Böylelikle PMB'nin } \\
\text { performansının artacağını ifade etmişlerdir. \%1.9 } \\
\text { Elvaloy } 4170 \text { ile modifiye edilen bitümlerde } \\
\text { jelleşme meydana geldiğini belirtmişlerdir. }\end{array}$ & $\begin{array}{l}\text { (Bulatovic } \\
\text { vd., 2014a; } \\
\text { Bulatovic } \\
\text { vd., 2012, } \\
\text { 2013, 2014b) }\end{array}$ \\
\hline 6 & VG 30 & $\begin{array}{l}\text { Elvaloy } \\
4170\end{array}$ & $\begin{array}{l}1.5, \\
1.8,2\end{array}$ & - & $\downarrow$ & $\uparrow$ & - & $\begin{array}{l}\text { Elvaloyun bitümü sertleştirdiğini belirlemişlerdir. } \\
\text { Ayrıca, \%2 RET ilavesinden elastik geri dönme } \\
\text { yüzdesinde artış meydana geldiğini ifade } \\
\text { etmişlerdir. }\end{array}$ & $\begin{array}{l}\text { (Vachhani ve } \\
\text { Mishra, } \\
\text { 2014) }\end{array}$ \\
\hline 7 & $\begin{array}{l}\mathrm{AC} \\
50 / 70\end{array}$ & $\begin{array}{l}\text { Elvaloy } \\
4170\end{array}$ & $\begin{array}{l}1.3 \\
1.6\end{array}$ & $\begin{array}{l}0.3 \\
0.5\end{array}$ & $\downarrow$ & $\uparrow$ & & $\begin{array}{l}\text { PE, SBS ve PPA ile modifiyeli bitümlerle } \\
\text { kıyaslandığında Elvaloy+PPA modifiyeli bitüm } \\
\text { saf bitümün penetrasyon değerini daha az } \\
\text { düşürüp yumuşama noktasını önemli derecede } \\
\text { arttırmıştır. }\end{array}$ & $\begin{array}{l}\text { (Domingos } \\
\text { vd., 2020; } \\
\text { Domingos ve } \\
\text { Faxina, } \\
\text { 2015a, } \\
\text { 2015b) }\end{array}$ \\
\hline 8 & $\begin{array}{l}\mathrm{AC} \\
60 / 70\end{array}$ & $\begin{array}{l}\text { Elvaloy } \\
4170\end{array}$ & $\begin{array}{l}1,2 \\
3,4\end{array}$ & - & $\downarrow$ & & $\downarrow$ & $\begin{array}{l}\text { Modifiyeli bitümlerin kıvamı ile ilgili yaptıkları } \\
\text { incelemede bitüme ilave edilen RET miktarı ile } \\
\text { doğru orantılı olarak bitümün kıvamını } \\
\text { sertleştirdiğini ifade etmişlerdir. }\end{array}$ & $\begin{array}{l}\text { (Irfan vd., } \\
\text { 2017) }\end{array}$ \\
\hline
\end{tabular}


Tablo 2. Devamı.

\begin{tabular}{|c|c|c|c|c|c|c|c|c|c|}
\hline \multirow[t]{2}{*}{ No } & \multirow{2}{*}{$\begin{array}{l}\text { Saf } \\
\text { Bitüm }\end{array}$} & \multirow{2}{*}{$\begin{array}{l}\text { RET } \\
\text { Türü }\end{array}$} & \multirow{2}{*}{$\begin{array}{l}\text { RET } \\
(\%)\end{array}$} & \multirow{2}{*}{$\begin{array}{l}\text { PPA } \\
(\%)\end{array}$} & \multicolumn{3}{|c|}{ RET etkisi } & \multirow[t]{2}{*}{ Bulgular } & \multirow[t]{2}{*}{ Referans } \\
\hline & & & & & Pen. & Y.N. & Dük. & & \\
\hline 9 & $\begin{array}{l}\text { PG 67- } \\
22\end{array}$ & $\begin{array}{l}\text { EMA- } \\
\text { GMA }\end{array}$ & 1.8 & $\begin{array}{ll}0.15- \\
0.3\end{array}$ & $\downarrow$ & $\uparrow$ & - & $\begin{array}{l}\text { RET'in tek başına kullanımının penetrasyon ve } \\
\text { yumuşama noktası üzerindeki etkisi düşük olurken } \\
\text { PPA ve HDPE ile kombine edilmesi bitümün } \\
\text { fiziksel özellikleri üzerindeki etkisini arttırmıştır. }\end{array}$ & $\begin{array}{l}\text { (Gama vd., } \\
\text { 2018) }\end{array}$ \\
\hline 10 & $\begin{array}{l}\mathrm{AC} \\
100 / 150\end{array}$ & $\begin{array}{l}\text { Elvaloy } \\
4170\end{array}$ & $\begin{array}{l}0.5 \\
0.75 \\
1\end{array}$ & 0.3 & $\downarrow$ & $\uparrow$ & $\downarrow$ & $\begin{array}{l}\text { Penetrasyon ve düktilitedeki düşüş ile yumuşama } \\
\text { noktasındaki artışı, bitümün sertleştiğinin ve } \\
\text { sıcaklık hassasiyetinde bir düşüş meydana } \\
\text { geldiğinin kanıtı olarak göstermişlerdir. }\end{array}$ & $\begin{array}{l}\text { (Geckil ve } \\
\text { Seloglu, } \\
\text { 2018) }\end{array}$ \\
\hline 11 & $\begin{array}{l}\mathrm{AC} \\
50 / 70\end{array}$ & $\begin{array}{l}\text { Elvaloy } \\
\text { RET }\end{array}$ & $\begin{array}{l}0.5 \\
1 \\
1.5 \\
2 \\
2.5\end{array}$ & 0.2 & $\downarrow$ & $\uparrow$ & $\downarrow$ & $\begin{array}{l}\% 1 \text { SBS ve \%1 EVA ile kompozit modifiyeli } \\
\text { bitüme ilave edilen RET miktarı ve karıştırma } \\
\text { süresi arttıkça penetrasyon ve düktilite değerleri } \\
\text { azalırken yumuşama noktası ve viskozite değerleri } \\
\text { artmıştır. }\end{array}$ & (Keyf, 2018) \\
\hline 12 & $\begin{array}{l}\text { AC } \\
80 / 100 \\
\text { AC } \\
200 / 300\end{array}$ & $\begin{array}{l}\text { Elvaloy } \\
5160\end{array}$ & - & - & $\downarrow$ & $\uparrow$ & - & $\begin{array}{l}\text { Elvaloy ve PPA modifiyeli AC } 200 / 300 \\
\text { penetrasyon sınıfindaki bitüm AC } 80 / 100 \\
\text { penetrasyon sınıfındaki saf bitümden daha sert bir } \\
\text { hale gelmiştir. }\end{array}$ & $\begin{array}{l}\text { (Skronka vd., } \\
\text { 2019) }\end{array}$ \\
\hline 13 & $\begin{array}{l}\mathrm{AC} \\
50 / 70\end{array}$ & $\begin{array}{l}\text { Elvaloy } \\
\text { RET }\end{array}$ & $\begin{array}{l}1, \\
1.25 \\
1.5 \\
1.75 \\
2\end{array}$ & 0.2 & $\downarrow$ & $\uparrow$ & $\downarrow$ & $\begin{array}{l}\text { RET ve PUP kompozit modifiyeli bitümlerde RET } \\
\text { miktarı arttıkça sertleşme artmıştır. }\end{array}$ & $\begin{array}{l}\text { (Xu vd., } \\
2019)\end{array}$ \\
\hline 14 & $\begin{array}{l}\mathrm{AC} \\
50 / 70\end{array}$ & $\begin{array}{l}\text { Elvaloy } \\
4170\end{array}$ & 1.5 & - & $\downarrow$ & $\uparrow$ & - & $\begin{array}{l}\text { Saf bitüme kıyasla Elvaloy modifiyeli bitümün } \\
\text { karıştırma ve sıkıştırma sıcaklıkları (ZSV ve SSF } \\
\text { metotları hariç) daha yüksek çıkmıştır. }\end{array}$ & $\begin{array}{l}\text { (Almusawi } \\
\text { vd., 2021a, } \\
2021 \text { b; } \\
\text { Almusawi } \\
\text { vd., 2019) }\end{array}$ \\
\hline
\end{tabular}

Tablo 2 incelendiğinde saf bitüme RET ilavesiyle saf bitümün penetrasyon ve düktilite değerlerinde azalma, yumuşama noktası değerinde ise artma meydana geldiği anlaşılmaktadır. Genel olarak, literatürde yapılmış olan tüm çalışmalarda saf bitümün fiziksel özellikleri üzerinde RET'in etkisi benzer şekilde bulunmuştur. $\mathrm{Bu}$ durum, RET modifikasyonun bitümde bir sertleşme meydana getirdiğinin göstergesidir. $\mathrm{Bu}$ sonuçlar doğrultusunda, RETMB'lerin yüksek iklim sıcaklıklarına sahip bölgelerde kullanıma uygun oldukları düşünülebilir.

Eğer bir polimer bitüme ilave edildiğinde saf bitümün penetrasyon değer aralığını çok fazla etkilemeden yumuşama noktasını arttırıp elastik özelliğini geliştiriyorsa o polimerin kullanıldığ PMB ile inşa edilecek kaplamanın hizmet ömrü boyunca iyi bir performans sergileyeceği düşünülür (Bulatovic vd., 2014a; Sengoz ve Isikyakar, 2008). Domingos ve Faxina (2015a), yaptıkları çalışmada RETMB'leri farklı polimerler ile modifiye edilmiş bitümlerle kıyaslamışlardır. Çalışmalarının sonucunda, RET'lerin saf bitümün penetrasyon değerine diğer polimerlere kıyasla daha az etki ettiğini ve yumuşama noktasını ise önemli bir miktarda arttırdığını belirlemişlerdir. Buradan da anlaşılacağ üzere, RET modifikasyonu fiziksel özellikler göz önüne alındığında saf bitümün performansında önemli bir artış sağlayabilmektedir.

\section{RET modifikasyonunun saf bitümün reolojik özelliklerine etkisi}

\subsection{RET'in viskozite ve işlenebirlilik üzerindeki etkisi}

Bir önceki bölümde belirtildiği üzere RET modifikasyonu bitümün kıvamını sertleştirmektedir. Genellikle, bitümlerin kıvamındaki sertleşmeyle paralel olarak viskozitelerinde de bir artış meydana gelir. Bitümlerin viskoziteleri dönel viskozite (RV) deneyi ile belirlenebilmektedir. Literatürde RETMB'ler üzerinde yapılan çalışmalardan, RV deneyi yürütülenler dikkate alındığında; bu çalışmaların hepsinde ortak sonuç olarak RETMB'nin saf bitüme kıyasla daha yüksek viskoziteye sahip olduğu ifade edilmiştir (Almusawi vd., 2021a, 2021b; Almusawi vd., 2019; Athira vd., 2020; Domingos ve Faxina, 
2015a, 2015b; Gama vd., 2018; Geckil, 2019; Geckil ve Seloglu, 2018; Hafeez ve Kamal, 2009; Keyf, 2015, 2018; Selvavathi vd., 2002; Topal, 2010; Vachhani ve Mishra, 2014; Xu vd., 2019). Buna ilaveten, bitüme ilave edilen RET miktarındaki artışla birlikte bitümün viskozitesinde de bir artış meydana gelmektedir (Geckil, 2019; Geckil ve Seloglu, 2018; Hafeez ve Kamal, 2009; Selvavathi vd., 2002; Topal, 2010; Vachhani ve Mishra, 2014).

Bitümün viskozitesinde meydana gelen artış saha koşullarında işlenebilirliğini düşürmektedir. Başka bir ifadeyle, yüksek viskoziteli bitümler ile hazırlanan bitümlü sıcak karışımların, karıştırılması ve serilip sıkıştırılması için bitümün normalden daha yüksek sicaklıklara 1sitılması gerekmektedir (Domingos ve Faxina, 2015a, 2015b; Singh vd., 2019b).

\subsection{RET'in tekerlek izi, yorulma ve düşük sicaklık çatlamaları üzerindeki etkisi}

Bir bitümün reolojik özelliklerine bakılarak kullanılacağ 1 kaplamanın performansını belirlemek mümkündür. $\mathrm{Bu}$ doğrulta, saf haldeki veya yaşlandırılmış bitüm numuneleri, dinamik kayma reometresi (DSR) yardımıyla, farklı sicaklıklarda, farklı frekanslarda veya yüklemelerde deneylere tabi tutularak çeşitli açılardan değerlendirilir (Zahoor vd., 2021). DSR deneyinden elde edilen iki ana parametre (kompleks kayma modülü $\mathrm{G}^{*}$ ve faz açısı $\delta$ ) yardımıyla tekerlek izi direnç parametresi $\mathrm{G}^{*} / \sin \delta$ bulunur (Oruc ve Yilmaz, 2016). Buna ilaveten, uzun süreli yaşlandırılmış bitüm numunelerine ortalama sicaklıklarda DSR deneyi uyguladiktan sonra yorulma direnci parametresi $\mathrm{G}^{*} \sin \delta$ belirlenerek yorulma dayanımı ile ilgili bir fikir edinilebilmektedir. Tablo 3'te literatürde RETMB'ler üzerinde inceleme yapılan çalışmalardan reolojik özellikler konusunda araştırma yürütülenleri verilmiştir. Çalışmalarda her bir numune için elde edilen değerleri tek bir tablo halinde vermek mümkün olmadığı için sadece çalışmalarda hangi parametrelerin belirlendiği ve hangi deneylerin yürütüldüğü işaretlenmiştir.

Tablo 3'e bakıldığında birçok çalışmada RETMB'lerin $G^{*} / \sin \delta$ değerlerinin belirlendiği görülmektedir. Genel olarak bu çalışmalarda, saf bitüme RET ilavesinin belirli bir sicaklıkta $\mathrm{G}^{*} / \sin \delta$ değerinde bir artışa sebep olduğu anlaşılmaktadır (Bagdat vd., 2015; Domingos ve Faxina, 2015b; Domingos vd., 2017; Geckil, 2019; Geckil ve Seloglu, 2018; Hafeez ve Kamal, 2009; Li vd., 2011; Liu vd., 2017; Singh vd., 2019b). Bu durum,
RET modifikasyonunun saf bitümün tekerlek izi direncini arttırdığını göstermektedir. Buna ilaveten, farklı oranlarda RET ilavesini inceleyen çalışmalarda ortak sonuç olarak RET miktarının artmasıyla tekerlek izine karşı direncin arttığ1 belirtilmiştir (Geckil, 2019; Geckil ve Seloglu, 2018). Benzer şekilde, $G^{*} \sin \delta$ parametreleri incelendiğinde de RETMB'lerin saf bitümlere karşı daha yüksek bir yorulma dayanımına sahip olduklarını söylemek mümkündür (Bagdat vd., 2015; Liu vd., 2017).

Tablo 3'te belirtilen bulgularla birlikte, ilerleyen zaman içerisinde daha yenilikçi deney yöntemleri RETMB'lerin reolojik özelliklerinin daha kapsamlı bir şekilde incelenmesini mümkün kılmıştır. En yenilikçi deney yöntemlerinden biri çoklu gerilme sünme ve geri dönme (MSCR) deneyidir. Tablo 3'te görüldüğü üzere RETMB'ler ile ilgili yapılan çalışmaların büyük bir çoğunluğunda MSCR deneyinden faydalanılmıştır. MSCR deneyi genellikle modifiyeli bitümün kalıcı deformasyon oluşturma potansiyelini belirlemek için kullanılır. MSCR ile modifiyeli bitümlerin gerilme altında gösterdikleri tepki, biri geri kazanılamayan sünme uyumu $\left(J_{\mathrm{nr}}\right)$ ve diğeri yüzde geri kazanım (\%) olmak üzere iki parametre üzerinden değerlendirilir. $J_{\mathrm{nr}}$ değerindeki artış tekerlek izine karşı dirençte bir düşüş anlamına gelmektedir (Zahoor vd., 2021). RETMB'lere uygulanan MSCR deneylerinin sonuçlarına göre saf bitüme kıyasla RETMB'lerin $J_{\text {nr }}$ değerlerinin daha düşük olduğu görülmüştür (Ali vd., 2018; Athira vd., 2020; Domingos vd., 2020; Domingos ve Faxina, 2015b; Domingos vd., 2017; Gama vd., 2018). Bu durum, DSR sonuçlarına benzer şekilde RETMB'lerin kalıcı deformasyona karşı dirençlerinin saf bitümlere kıyasla daha yüksek olduğunu belirtmektedir.

Bitümlerin reolojisi ile incelenebilen diğer konu, düşük sıcaklıklarda meydana gelen isıl çatlaklara karşı bitümlerin direncidir. Bununla ilgili olarak, uzun dönemli yaşlandırmaya maruz bırakılmış bitümlere kiriş eğme reometresi (BBR) deneyi uygulanır. Bu deney sonucunda sünme rijitliği (S) ve m-değeri olmak üzere iki farklı parametre belirlenir. $\mathrm{Bu}$ parametreler doğrultusunda bitümlerin düşük sıcaklıklardaki performansları belirlenir. Tablo 3'te RET ile ilgili çalışmalarda S ve m-değeri parametrelerinin incelendiği çalışmalar gösterilmiştir. Bu çalışmalardan sadece bir tanesinde (Bagdat vd., 2015) RET modifikasyonunun saf bitümün düşük sıcaklık performansını iyileştirdiği yönünde bir sonuç elde edilmişken diğerlerinde (Geckil, 2019; Geckil ve Seloglu, 2018; Irfan vd., 2017; Xu vd., 2020; Xu 
vd., 2019) RET modifikasyonunun saf bitümün düşük sicaklık performansını düşürdüğü belirlenmiştir. Buna ilaveten, modifikasyondaki
RET miktarı artıkça düşük sıcaklık çatlaklarına karş1 direncin azaldığ1 görülmüştür (Geckil, 2019; Geckil ve Seloglu, 2018; Irfan vd., 2017).

Tablo 3. RETMB'lerin reolojisi ile ilgili yapılan çalışmalar.

\begin{tabular}{|c|c|c|c|c|c|c|c|c|c|c|c|c|c|c|}
\hline \multirow[t]{2}{*}{ No } & \multirow{2}{*}{$\begin{array}{l}\text { Saf } \\
\text { Bitüm }\end{array}$} & \multirow{2}{*}{$\begin{array}{l}\text { RET } \\
\text { Türü }\end{array}$} & \multirow{2}{*}{$\begin{array}{l}\text { RET } \\
(\%)\end{array}$} & \multirow{2}{*}{$\begin{array}{l}\text { PPA } \\
(\%)\end{array}$} & \multicolumn{8}{|c|}{ Reolojik etki } & \multirow{2}{*}{$\begin{array}{l}\text { Perf. } \\
\text { sinıfi }\end{array}$} & \multirow[t]{2}{*}{ Referans } \\
\hline & & & & & G* & $\delta$ & $G * / \sin \delta$ & $G * \sin \delta$ & $S(t)$ & $\begin{array}{l}\text { m- } \\
\text { değeri }\end{array}$ & MSCR & Diğer & & \\
\hline 1 & $\begin{array}{l}\mathrm{AC} \\
70 / 100\end{array}$ & $\begin{array}{l}\text { Elvaloy } \\
\text { AM; } \\
\text { Elvaloy } \\
4170\end{array}$ & $\begin{array}{l}1,1.5, \\
1.75, \\
2,2.5\end{array}$ & - & & & & & & & & $\begin{array}{l}\text { G', G", } \\
\tan (\delta) \\
\text { Master } \\
\text { eğrileri }\end{array}$ & - & $\begin{array}{l}\text { (Polacco } \\
\text { vd., 2004a) }\end{array}$ \\
\hline 2 & $\begin{array}{l}\mathrm{AC} \\
60 / 70\end{array}$ & $\begin{array}{l}\text { Elvaloy } \\
\text { RE }\end{array}$ & 2 & - & & & & & & & & $\begin{array}{l}\mathrm{G}^{\prime}, \mathrm{G} ", \\
\tan (\delta) \\
\text { Master } \\
\text { eğrileri }\end{array}$ & - & $\begin{array}{l}\text { (Pérez- } \\
\text { Lepe vd., } \\
\text { 2007) }\end{array}$ \\
\hline 3 & $\begin{array}{l}\mathrm{AC} \\
60 / 70\end{array}$ & $\begin{array}{l}\text { Elvaloy } \\
4170\end{array}$ & $\begin{array}{l}1,1.5, \\
1.75 \\
2\end{array}$ & 0.2 & & $\checkmark$ & $\checkmark$ & & & & & & $\begin{array}{l}\text { PG 70-xx } \\
\text { PG 76-xx } \\
\text { PG 82-xx } \\
\text { PG 82-xx }\end{array}$ & $\begin{array}{l}\text { (Hafeez ve } \\
\text { Kamal, } \\
\text { 2009) }\end{array}$ \\
\hline 4 & $\begin{array}{l}\text { PG 52- } \\
34\end{array}$ & Elvaloy & 1.1 & 0.3 & & & $\checkmark$ & & & & $\checkmark$ & & PG 64-34 & $\begin{array}{l}\text { (Li vd., } \\
\text { 2011) }\end{array}$ \\
\hline 5 & $\begin{array}{l}\mathrm{AC} \\
50 / 70, \\
\mathrm{AC} \\
70 / 100\end{array}$ & $\begin{array}{l}\text { Elvaloy } \\
\text { AM, } \\
\text { Elvaloy } \\
4170\end{array}$ & $\begin{array}{l}1.6, \\
1.9\end{array}$ & - & $\checkmark$ & $\checkmark$ & & & & & & $\begin{array}{l}\text { Master } \\
\text { eğrileri }\end{array}$ & - & $\begin{array}{l}\text { (Bulatovic } \\
\text { vd., 2014a; } \\
\text { Bulatovic } \\
\text { vd., 2012, } \\
2013 \text {, } \\
2014 \mathrm{~b} \text { ) }\end{array}$ \\
\hline 6 & $\begin{array}{l}\mathrm{AC} \\
90 / 130\end{array}$ & $\begin{array}{l}\text { Elvaloy } \\
4170\end{array}$ & 1.4 & - & $\checkmark$ & $\checkmark$ & $\checkmark$ & $\checkmark$ & $\checkmark$ & $\checkmark$ & & & PG 82-35 & $\begin{array}{l}\text { (Bagdat } \\
\text { vd., 2015) }\end{array}$ \\
\hline 7 & $\begin{array}{l}\mathrm{AC} \\
50 / 70\end{array}$ & $\begin{array}{l}\text { Elvaloy } \\
4170\end{array}$ & 1.3 & 0.3 & $\checkmark$ & $\checkmark$ & $\checkmark$ & & & & & $\begin{array}{l}\text { Master } \\
\text { eğrileri }\end{array}$ & PG 76-xx & $\begin{array}{l}\text { (Domingos } \\
\text { ve Faxina, } \\
\text { 2015a) }\end{array}$ \\
\hline 8 & $\begin{array}{l}\mathrm{AC} \\
50 / 70\end{array}$ & $\begin{array}{l}\text { Elvaloy } \\
4170\end{array}$ & 1.3 & 0.3 & & & & & & & $\checkmark$ & & PG 76-xx & $\begin{array}{l}\text { (Domingos } \\
\text { ve Faxina, } \\
2015 b \text { ) }\end{array}$ \\
\hline 9 & $\begin{array}{l}\mathrm{AC} \\
50 / 70\end{array}$ & $\begin{array}{l}\text { Elvaloy } \\
4170\end{array}$ & 0.6 & 0.2 & & & & & & & & $\begin{array}{l}\text { Çekmede } \\
\text { sünme ve } \\
\text { geri } \\
\text { kazanım } \\
\text { modelle- } \\
\text { meleri }\end{array}$ & PG 82-22 & $\begin{array}{l}\text { (Hampl vd., } \\
2015 \text { ) }\end{array}$ \\
\hline 10 & $\begin{array}{l}\mathrm{AC} \\
50 / 70\end{array}$ & $\begin{array}{l}\text { Elvaloy } \\
4170\end{array}$ & 0.6 & 0.2 & & & & & & & & $\begin{array}{l}\text { G', G", } \\
\tan (\delta) \\
\text { Master } \\
\text { eğrileri }\end{array}$ & - & $\begin{array}{l}\text { (Jasso vd., } \\
\text { 2015) }\end{array}$ \\
\hline 11 & $\begin{array}{l}\mathrm{AC} \\
60 / 70\end{array}$ & $\begin{array}{l}\text { Elvaloy } \\
\text { RET }\end{array}$ & 1.35 & $1.4 \mathrm{~g}$ & $\checkmark$ & $\checkmark$ & & & & & & & - & $\begin{array}{l}\text { (Javid, } \\
\text { 2016) }\end{array}$ \\
\hline 12 & $\begin{array}{l}\mathrm{AC} \\
50 / 70\end{array}$ & $\begin{array}{l}\text { Elvaloy } \\
4170\end{array}$ & 1.6 & 0.5 & & & $\checkmark$ & & & & $\checkmark$ & & PG 76-xx & $\begin{array}{l}\text { (Domingos } \\
\text { vd., 2017) }\end{array}$ \\
\hline 13 & $\begin{array}{l}\text { PG 64- } \\
22\end{array}$ & RET & 3 & - & & & $\checkmark$ & $\checkmark$ & $\checkmark$ & $\checkmark$ & $\checkmark$ & & PG 76-22 & $\begin{array}{l}\text { (Liu vd., } \\
\text { 2017) }\end{array}$ \\
\hline 14 & VG-30 & Elvaloy & 1.6 & 0.3 & & & & & & & $\checkmark$ & $\begin{array}{l}\text { Doğrusal } \\
\text { genlik } \\
\text { taramas1 } \\
\text { (LAS) }\end{array}$ & - & $\begin{array}{l}\text { (Singh vd., } \\
\text { 2017) }\end{array}$ \\
\hline
\end{tabular}


Tablo 3. Devami.

\begin{tabular}{|c|c|c|c|c|c|c|c|c|c|c|c|c|c|}
\hline \multirow[t]{2}{*}{ No } & \multirow{2}{*}{$\begin{array}{l}\text { Saf } \\
\text { Bitüm }\end{array}$} & \multirow{2}{*}{$\begin{array}{l}\text { RET } \\
\text { Türü }\end{array}$} & \multirow{2}{*}{$\begin{array}{l}\text { RET } \\
(\%)\end{array}$} & \multirow{2}{*}{$\begin{array}{l}\text { PPA } \\
(\%)\end{array}$} & \multicolumn{7}{|c|}{ Reolojik etki } & \multirow{2}{*}{$\begin{array}{l}\text { Perf. } \\
\text { sinıfı }\end{array}$} & \multirow[t]{2}{*}{ Referans } \\
\hline & & & & & G* & $\delta$ & $G^{*} / \sin \delta$ & $G * \sin \delta$ & $\mathbf{S}(\mathbf{t})$ & $\begin{array}{l}\text { m- } \\
\text { değeri }\end{array}$ & MSCR Diğer & & \\
\hline 15 & $\begin{array}{l}\mathrm{AC} \\
40 / 50, \\
\mathrm{AC} \\
60 / 80, \\
\mathrm{AC} \\
80 / 100\end{array}$ & $\begin{array}{l}\text { Elvaloy } \\
\text { RET; } \\
\text { Elvaloy } \\
\text { AC }\end{array}$ & $\begin{array}{l}1.35, \\
1.7, \\
2 ; \\
2.5, \\
3.5, \\
4.5\end{array}$ & 0.2 & & & & & & & $\checkmark$ & - & $\begin{array}{l}\text { (Ali vd., } \\
\text { 2018) }\end{array}$ \\
\hline 16 & $\begin{array}{l}\text { PG 67- } \\
22\end{array}$ & $\begin{array}{l}\text { EMA- } \\
\text { GMA }\end{array}$ & 1.8 & $\begin{array}{l}0.15- \\
0.3\end{array}$ & & & & & & & $\checkmark$ & $\begin{array}{l}\text { PG 76E- } \\
22 \text { PG } \\
82 E-22\end{array}$ & $\begin{array}{l}\text { (Gama vd., } \\
\text { 2018) }\end{array}$ \\
\hline 17 & $\begin{array}{l}\mathrm{AC} \\
100 / 150\end{array}$ & $\begin{array}{l}\text { Elvaloy } \\
4170\end{array}$ & $\begin{array}{l}0.5 \\
0.75 \\
1\end{array}$ & 0.3 & $\checkmark$ & $\checkmark$ & $\checkmark$ & $\checkmark$ & $\checkmark$ & $\checkmark$ & & $\begin{array}{l}\text { PG 64-xx } \\
\text { PG 70-xx } \\
\text { PG 70-xx }\end{array}$ & $\begin{array}{l}\text { (Geckil ve } \\
\text { Seloglu, } \\
2018 \text { ) }\end{array}$ \\
\hline 18 & $\begin{array}{l}\mathrm{AC} \\
160 / 220\end{array}$ & $\begin{array}{l}\text { Elvaloy } \\
5160\end{array}$ & $\begin{array}{l}0.4, \\
0.8, \\
1.2\end{array}$ & 0.3 & $\checkmark$ & $\checkmark$ & $\checkmark$ & $\checkmark$ & $\checkmark$ & $\checkmark$ & & $\begin{array}{l}\text { PG 58-22 } \\
\text { PG 64-22 } \\
\text { PG 70-16 }\end{array}$ & $\begin{array}{l}\text { (Geckil, } \\
\text { 2019) }\end{array}$ \\
\hline 19 & VG-30 & Elvaloy & 1.6 & 0.3 & $\checkmark$ & & $\checkmark$ & & & & $\checkmark$ & PG 76-xx & $\begin{array}{l}\text { (Singh vd., } \\
\text { 2019a) }\end{array}$ \\
\hline 20 & $\begin{array}{l}\mathrm{AC} \\
50 / 70\end{array}$ & $\begin{array}{l}\text { Elvaloy } \\
\text { RET }\end{array}$ & $\begin{array}{l}1, \\
1.25, \\
1.5, \\
1.75, \\
2\end{array}$ & 0.2 & & & & & $\checkmark$ & $\checkmark$ & $\checkmark$ & - & $\begin{array}{l}\text { (Xu vd., } \\
\text { 2020; Xu } \\
\text { vd., 2019) }\end{array}$ \\
\hline 21 & VG-30 & $\begin{array}{l}\text { TERP1 } \\
\text { TERP2 }\end{array}$ & 3.5 & - & & & $\checkmark$ & & & & $\checkmark$ & $\begin{array}{l}\text { PG 81-xx } \\
\text { PG 82-xx }\end{array}$ & $\begin{array}{l}\text { (Athira } \\
\text { vd., 2020) }\end{array}$ \\
\hline 22 & $\begin{array}{l}\mathrm{AC} \\
50 / 70\end{array}$ & $\begin{array}{l}\text { Elvaloy } \\
4170\end{array}$ & 1.6 & 0.5 & & & $\checkmark$ & & & & $\checkmark$ & PG 70-xx & $\begin{array}{l}\text { (Domingos } \\
\text { vd., 2020) }\end{array}$ \\
\hline
\end{tabular}

\section{RET modifikasyonunun asfalt karışımların performansı üzerindeki etkisi}

İçerisinde RETMB bulunduran asfalt karışım numunelerine bir takım deneyler uygulayarak asfalt kaplamanın performansı üzerinde fikir edinmek mümkündür. Bu deney yöntemlerinden en yaygın olan iki tanesi Marshall stabilite deneyi ile tekerlek izi deneyidir. Literatürde RETMB'ler ile ilgili yapılan çalışmaların büyük bir çoğunluğunda asfalt karışım deneylerine yer verilmemiş olmakla birlikte, belirtilen deneylerin yürütüldügü çalışmalar da bulunmaktadır (Almusawi vd., 2021a; Athira vd., 2020; Irfan vd., 2017; Selvavathi vd., 2002; Skronka vd., 2019; Xu vd., 2020; Xu vd., 2019).

RETMB'lerin, asfalt karışım numunelerinin Marshall stabilite değerlerine etkisini inceleyen çalışmalara bakıldığında bu çalışmalardaki sonuçların birbirlerine paralel olduğu görülmektedir. Saf bitümle hazırlanmış asfalt karışım numunelerinin Marshall stabilite değerlerine kıyasla RETMB'lerle hazırlanan asfalt karışım numunelerinin Marshall stabilite değerleri daha yüksektir (Almusawi vd., 2021a; Athira vd., 2020; Irfan vd., 2017; Selvavathi vd., 2002; Xu vd.,
2020; Xu vd., 2019). Bu sonuçlar, RETMB'ler kullanılarak hazırlanacak asfalt kaplamaların saf bitümle hazırlanacaklara kıyasla tekerlek izi dayanımı dikkate alındığında daha iyi performans sergileyeceklerini ifade etmektedir.

RETMB'lerin tekerlek izi direnci açısından asfalt karışımlar üzerindeki etkisi incelendiğinde bu konuda yapılan çalışmaların sonuçlarının da birbirleriyle paralel olduğunu görmek mümkündür. RETMB ile hazırlanan asfalt karışım numuneleri tekrarlı yük geçişleri sonrasında saf bitüm ile hazırlanan asfalt karışımlara kıyasla daha az deformasyon göstermişlerdir (Athira vd., 2020; Irfan vd., 2017; Xu vd., 2020; Xu vd., 2019). Burada bulunan sonuçlar, RETMB'ler üzerinde yapılan reolojik araştırmaların sonuçları ile paralel bir şekilde, RETMB'ler ile hazırlanan asfalt kaplamaların saf bitümle hazırlanan asfalt kaplamalara kıyasla tekerlek izi oluşumuna karşı daha yüksek dirence sahip olduğunu göstermektedir.

Li vd. (2011) yaptıkları çalışmada, PPA'nın ve PPA ile birlikte SBS veya Elvaloy kullanımının, asfalt karışım numunelerine ait dinamik modül değerleri üzerindeki etkisine yer vermişlerdir. 
Farklı frekanslarla uyguladıkları ve viskoelastik sürekli hasar konsepti ile normalleştirdikleri dinamik modül deneyleri doğrultusunda, Elvaloy ve PPA modifiyeli bitümle (RETMB) hazırlanan asfalt karışım numunelerinin yüksek frekans (düşük sıcaklık) bölgesinde en düşük sertliğe, düşük frekans (yüksek sıcaklık) bölgesinde ise en yüksek sertliğe sahip olduğunu belirlemişlerdir. Bu durum, yüksek sıcaklıklarda kalıcı deformasyona karş1 en iyi direncin RETMB ile hazırlanan asfalt karışımlarda sağlanabileceğini belirtmektedir. Buna ilaveten, düşük sıcaklıklarda da RETMB kullanılarak hazırlanacak asfalt kaplamanın da sahip olacağı düşük rijitlikten dolayı düşük sıcaklıklarda gevrek bir davranış sergilemeyeceği düşünülebilir. Li vd. (2011) aynı çalışmada, yorulma olayının gözlemlendiği ortalama s1caklıklarda (ortalama frekanslarda) hazırladıkları tüm asfalt karışım numunelerinin benzer dinamik modüllere sahip olduğunu belirterek, bu numunelere tekrarlı yük uygulamış ve yorulma olayına karşı dirençlerini kıyaslamışlarıdır. Bunun sonucunda, RETMB ile hazırlanan asfalt karışım numunesinin en yüksek yorulma direncine sahip olduğunu belirtmişlerdir.

RETMB ile hazırlanan asfalt karışımların yorulma direnci ile ilgili veriye yer verilen bir başka çalışma da Domingos vd. (2017)'nin yaptığ çalışmadır. Bu çalışmada, aynı PG'lere sahip modifiyeli bitümlerle asfalt karışım numuneleri hazırlanmış ve $60^{\circ} \mathrm{C}$ sicaklıkta tekrarlı yüklemelere maruz bırakılan numuneler için akma sayıları $\left(\mathrm{F}_{\mathrm{N}}\right)$ belirlenmiştir. Saf bitüm ve Elvaloy+PPA, SBS, SBS+PPA, SBR, SBR+PPA modifiyeli bitümlerle hazırlanan asfalt karışımlar için $\mathrm{F}_{\mathrm{N}}$ değerleri sirasiyla; 2167, 7050, 4991, 6110, 3312, 5875 olarak belirlenmiştir. Buradan anlaşılacağı üzere, tüm modifiyeli bitümler arasında en yüksek yorulma direncine RETMB sahiptir. Buna ilaveten, RETMB ile hazırlanan asfalt karışım, saf bitümle hazırlanana kıyasla, 3.25 kat daha iyi yorulma performansı sergilemiştir.

RETMB ile hazırlanan asfalt karışımlarla ilgili bilgiye, her ne kadar temelinde kompozit modifikasyonu irdeleyen bir çalışma olsa da, Xu vd. (2019)'nin yaptığ erişilebilmektedir. Bu çalışmada, saf bitüm ve RETMB ile hazırlanan asfalt karışımların dinamik stabilitelerine, eğme kirişi deneyi sonuçlarına, donma-çözünmede bölünme deneyi ve nem hasarlı Marshall stabilite oranlarına yer verilmiştir. Dinamik stabilite deneyi sonuçlarında kalıcı deformasyona karşı direncin, diğer çalışmalarla benzer şekilde (Li vd., 2011), RETMB ile hazırlanan asfalt karışımlarda saf bitümle hazırlananlara kıyasla daha yüksek olduğunu belirlemişlerdir. Düşük sıcaklıklarda asfalt karışım numunesinde meydana gelen çatlaklara karşı direnç incelendiğinde ise saf bitümlü numune ile RETMB'li numune arasında çok büyük bir fark çıkmamakla birlikte RETMB'li numune yaklaşık $\% 5$ daha yüksek direnç göstermiştir. Nem hasarına karşı direnç dikkate alındığında ise, RETMB ile hazırlanan asfalt karışım numunesinin, saf bitümle hazırlanana kıyasla, daha yüksek dirence sahip olduğunu ifade etmişlerdir.

\section{Kompozit modifikasyonda RET kullanımı}

Birden fazla katkı maddesinin bir arada kullanımı ile elde edilen kompozit modifiyeli bitümlerin incelendiği çalışmalar literatürde yaygınlaşmaktadırlar. Kompozit modifikasyonun en büyük özelliği bitüme farklı özellikler katan katkı maddelerinin bir arada kullanılması ile bitümün özelliklerinin birçok açıdan iyileştirilmesini mümkün kılmasıdır.

RETMB'ler ile ilgili yapılan çalışmalarda kompozit modifikasyona ilk olarak Keyf vd. (2007b) yer vermiştir. Bu çalışmalarında farklı oranlarda RET ile birlikte sabit oranda etilen terpolimer kullanımı incelemişler ve fiziksel açıdan bitümün performansının arttığını belirlemişlerdir. Yaptıkları bir başka çalışmada ise sabit oranda RET ile birlikte farklı oranda etilen terpolimer kullanımını incelemiş̧lerdir (Keyf vd., 2007a). İlerleyen y1llarda Keyf; SBS, RET ve EVA katk1 malzemelerinin farkl1 oranlarda kullanımlarını içeren kompozit modifiyeli bitümler üzerinde çalışmalar yürütmüştür (Keyf, 2010; 2015; 2018). İlk çalışmasında, SBS ve Elvaloy ile modifiye edilen bitümün penetrasyon indeksinde büyük bir artışın meydana geldiğini ve böylece sıcaklık değişiminden daha az etkilenen bir modifiyeli bitümün elde edilebileceğini tespit etmiştir (Keyf, 2010). Diğer çalışmasında (Keyf, 2015), \%1 RET, \%1 SBS ve \%0.5, 1, 1.5, 2, 2.5 EVA katkılı bitümleri incelemiş ve \%1 RET, \%1 SBS ve \%2.5 EVA modifiyeli bitümü, bu katk1 maddelerinin ayrı ayr1 \%4.5 oranında kullanımını inceleyen literatürdeki çalışmalarla kıyaslamıştır. Sonuç olarak kompozit modifikasyonun bitümün özelliklerini geliştirmede daha etkili olduğunu belirlemiştir. Son çalışmasında ise (Keyf, 2018), $\% 0.5,1,1.5,2,2.5$ RET, \%1 SBS ve \%1 EVA modifiyeli bitümleri incelemiştir. \%2-2.5 aralığında RET ilavesinin bir çapraz bağ oluşumunu sağladığını ve bitümün performans özelliklerinin ani bir şekilde değiştiğini belirlemiştir. 
RET modifikasyonu, daha önceki bölümlerde ifade edildiği gibi bitümlerin işlenebilirliğini azaltmakta ve düşük sıcaklık performansını düşürmekte veya etkilememektedir. $\mathrm{Bu}$ dezavantajların giderilmesi için kompozit modifikasyonun incelendiği çalışmalar mevcuttur (Singh vd., 2019a; Singh vd., 2017, 2019b; Singh vd., 2018; Xu vd., 2020; Xu vd., 2019). Singh ve çalışma arkadaşları yaptıkları çalışmalarda RETMB'lere işlenebilirliklerini arttırmak amaciyla 1lık asfalt katkı malzemeleri ve sönmüş kireç ilave etmişler ve bitümlerin performanslarındaki değişimleri incelemişlerdir (Singh vd., 2019a; Singh vd., 2017, 2019b; Singh vd., 2018). Çalışmalarda ortak sonuç olarak performanslardaki değişimin kullanılan ılık asfalt katkısına göre değişkenlik gösterdiği belirlenmiştir. Detaylı sonuçlar için okurların referansları incelemesi önerilmektedir.

RET modifikasyonunun bir diğer dezavantajı olan düşük sıcaklık performansı da kompozit modifikasyon ile arttırılmaya çalışılmıştır (Xu vd., 2020; Xu vd., 2019). Bu çalışmalardan ilkinde, farklı oranlarda RET ve PUP birlikte kullanılarak performans üzerindeki etkiler incelenmiştir. Çalışmaların sonucunda PUP ilavesinin RETMB'lerin düşük sıcaklık performansını önemli derecede arttırdığını belirlemişlerdir (Xu vd., 2019). Diğer çalışmada ise asfalt karışım numuneleri hazırlayarak agrega ile birlikte GWR ve farklı türdeki fiberleri RETMB'lerle hazırlanan asfalt karışımlara ilave etmişlerdir. Bu kompozit modifikasyonun da RET modifiyeli asfalt karışımların düşük sıcaklık performansında artış sağladığını belirtmişlerdir (Xu vd., 2020).

RET içeren kompozit modifiyeli bitümler üzerine yapılan çalışmalardan anlaşıldığı üzere kompozit modifikasyon saf bitümün özelliklerinin farklı açılardan daha etkili bir şekilde geliştirilmesini mümkün kılmaktadır. Fakat böylesi umut vadeden sonuçlara rağmen, bu konuda literatürde yapılan çalışmaların sayısı ve çeşitliliği oldukça azdır. Literatürde bulunan diğer katkı malzemeleri ile birlikte RET'lerin kullanımının bitüm üzerindeki etkisinin incelenmesi halen araştırmaya açık bir konu olarak görülmektedir.

\section{Tartışma ve sonuçlar}

$\mathrm{Bu}$ derleme çalışmasında, RETMB'ler ile ilgili literatürdeki çalışmalar incelenmiştir. $\mathrm{Bu}$ çalışmalardan RETMB'lerin hazırlanışı ve bitümün performansı üzerindeki etkisi ile ilgili bilgiler toparlanmıştır. Buna ilaveten, RETMB'lerin kullanılacağı asfalt kaplamaların performansı hakkında, yapılan çalışmalardan edinilen bilgilere yer verilmiştir. Son olarak ise kompozit modifikasyonda RET'lerin yerine değinilmiştir. Bu çalışmanın sonuçları aşağıdaki gibi özetlenebilir:

- RETMB'lerin hazırlanması için literatürde tercih edilen karıştırma parametreleri farklılıklar göstermektedir. Karışım hazırlama koşullarındaki farklılıklar çalışmaların birbirleriyle kıyaslanmasını zorlaştırmaktadır. Bununla birlikte çalışmaların genelinde, 175$185{ }^{\circ} \mathrm{C}$ sıcaklık ve 2 saat karıştırma süresi tercih edilmiştir.

- RETMB'lerin fiziksel özellikleri ile ilgili çalışmalar incelendiğinde RET modifikasyonunun saf bitümün penetrasyon ve düktilite değerlerini azalttığ $\breve{g}_{\text {, yumuşama }}$

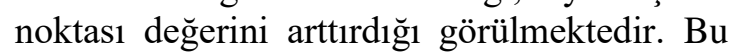
durum RET'in saf bitümde bir sertleşme sağladığııı göstermektedir.

- RETMB'lerin reolojik özellikleri ile ilgili çalışmalar incelendiğinde RET modifikasyonunun saf bitümün yüksek sıcaklıklardaki performansını arttırdığg, düşük sıcaklıklardaki performansına etki etmediği veya kötü yönde etkilediği belirlenmiştir. RET ilavesi saf bitümün viskozitesini, yorulma direncini ve tekerlek izine karşı direncini arttırmıştır.

- RETMB'ler ile hazırlanan asfalt karışım numunelerinin incelendiği çalışmalarda RET modifikasyonunun karışımın performansını arttırdığı belirlenmiştir. RET ilavesi ile karışımın tekerlek izinde çökme miktarı azalmış ve Marshall stabilite değeri artmıştır.

- Kompozit modifikasyonda RET'lere yer verilen çalışmalar incelendiğinde, RETMB'lerin dezavantajlarını gidermek amacıyla bu katkı malzemelerinin farklı katk1 malzemeleri ile kombine edilmesinin olumlu sonuçlar verdiği anlaşılmıştır. Ancak, bu alanda yapılan çalışma sayısının az ve çeşitliliğinin kısıtllı olduğu düşünülmektedir.

$\mathrm{Bu}$ çalışma sonucunda RET'in kompozit modifikasyonu ile ilgili yapılan çalışmaların sayısının ve çeşitliliğinin artmasının literatüre katkı sağlayacağ1 düşünülmektedir. Ayrıca, literatürde RETMB hazırlanması esnasında tercih edilen karışım koşulları ile ilgili bir bütünlük görülemediğinden farklı karıştırma koşullarının bitümün özellikleri üzerindeki etkisi göz önüne alınarak optimum karıştırma koşullarının belirlenmesinin faydalı olacağı düşünülmektedir. 


\section{Kaynaklar}

Airey, G. D. (2002). Rheological evaluation of ethylene vinyl acetate polymer modified bitumens. Construction and Building Materials, 16(8), 473$487 . \quad$ https://doi.org/10.1016/S09500618(02)00103-4.

Al-Hadidy, A. I. and Tan, Y. Q. (2009). Mechanistic analysis of ST and SBS-modified flexible pavements. Construction and Building Materials, 23(8), 2941-2950. https://doi.org/10.1016/j.conbuildmat.2009.02.0 23.

Alam, G., Hafeez, I., Yaseen, G., Nasir, M. A., Hussain, A. and Ahmad, N. (2020). Assessing the aging tendency of asphalt binder using a thermal cycler. International Journal of Pavement Engineering, 1-12. https://doi.org/10.1080/10298436.2020.1861279

Ali, A., ur Rehman, Z., Farooq, U. and Mirza, M. W. (2018). Evaluation of rutting potential of polymer modified asphalt binder using multiple stress creep and recovery method. Pakistan Journal of Engineering and Applied Sciences, 22(1), 64-71.

Almusawi, A., Sengoz, B. and Topal, A. (2021a). Evaluation of mechanical properties of different asphalt concrete types in relation with mixing and compaction temperatures. Construction and Building Materials, 268, 121140. https://doi.org/10.1016/j.conbuildmat.2020.1211 40.

Almusawi, A., Sengoz, B. and Topal, A. (2021b). Investigation of mixing and compaction temperatures of modified hot asphalt and warm mix asphalt. Periodica Polytechnica Civil Engineering, $\quad 65(1), \quad$ 72-83. https://doi.org/10.3311/PPci.15118.

Almusawi, A., Sengoz, B., Topal, A. and Oner, J. (2019). Comparison between zero shear viscosity and steady shear flow methods to determine mixing and compaction temperatures of PMB. Eurasian Journal of Civil Engineering and Architecture, 3(2), 1-8.

Athira, P. K., Atul Narayan, S. P., Murali Krishnan, J. and Jain, P. K. (2020). Comparison of binder and mixture tests to characterize permanent deformation of elastomer and terpolymer modified binders. Construction and Building Materials, $264, \quad 120138$. https://doi.org/10.1016/j.conbuildmat.2020.1201 38.

Bagdat, T., Galiya, I. and Yerik, A. (2015). Rheological properties of oxidized bitumen with polymer additive. Journal of Applied Sciences, 15(1), 129-137.

Bhurke, A. S., Shin, E. E. and Drzal, L. T. (1997). Fracture morphology and fracture toughness measurement of polymer-modified asphalt concrete. Asphalt Mixture Quality, Characteristics, and Performance (1590), 23-33.

Bricker, R. M. and Hesp, S. A. M. (2013). Modulated differential scanning calorimetry study of physical hardening rates in asphalt cements. 2013 Airfield \& Highway Pavement Conference (pp. 955-966). Los Angeles, California, United States.

https://doi.org/10.1061/9780784413005.079.

Brule, B., Brion, Y. and Tanguy, A. (1988). Paving asphalt polymer blends: Relationships between composition, structure and properties (with discussion). Association of Asphalt Paving Technologists Proc (pp. 41-64).

Bulatovic, V. O., Rek, V. and Markovic, J. (2014a). Rheological properties of bitumen modified with ethylene butylacrylate glycidylmethacrylate. Polymer Engineering and Science, 54(5), 10561065. https://doi.org/10.1002/pen.23649.

Bulatovic, V. O., Rek, V. and Markovic, K. J. (2012). Permanent deformation of polymer modified bitumen. Road and Rail Infrastructure Ii, 317326.

Bulatovic, V. O., Rek, V. and Markovic, K. J. (2013). Influence of polymer types on bitumen engineering properties. Materials Research Innovations, 17(3), 189-194. https://doi.org/10.1179/1433075x12y.00000000 59.

Bulatovic, V. O., Rek, V. and Markovic, K. J. (2014b). Effect of polymer modifiers on the properties of bitumen. Journal of Elastomers and Plastics, 46(5), 448-469. https://doi.org/10.1177/0095244312469964.

Chiono, V., Filippi, S., Yordanov, H., Minkova, L. and Magagnini, P. (2003). Reactive compatibilizer precursors for LDPE/PA6 blends. III: ethyleneglycidylmethacrylate copolymer. Polymer, 44(8), 2423-2432. https://doi.org/10.1016/S0032-3861(03)001344.

Collins, J., Bouldin, M., Gelles, R. and Berker, A. (1991). Improved performance of paving asphalts by polymer modification (with discussion). Journal of the Association of Asphalt Paving Technologists, 60, 43-79.

Connan, J., Jones, M. K., Briggs, D. E. G., Eglington, G. and Hagelberg, E. (1999). Use and trade of bitumen in antiquity and prehistory: molecular 
archaeology reveals secrets of past civilizations. Philosophical Transactions of the Royal Society of London. Series B: Biological Sciences, 354(1379), 33-50.

https://doi.org/10.1098/rstb.1999.0358.

de Sá Araujo, M. d. F. A., Lins, V. d. F. C., Pasa, V. M. D. and Leite, L. F. M. (2013). Weathering aging of modified asphalt binders. Fuel Processing Technology, 115, 19-25. https://doi.org/10.1016/j.fuproc.2013.03.029.

Domingos, M. D. I., Faxina, A. and Bernucci, L. L. B. (2020). Rutting on asphalt binders and mixtures modified with PPA and Elvaloy ${ }^{\circledR}$ : laboratory aspects and rheological modeling. $34^{\circ}$ Congresso de Pesquisa e Ensino em Transporte da ANPET (pp. 1275-1286).

Domingos, M. D. I. and Faxina, A. L. (2015a). Accelerated short-term ageing effects on the rheological properties of modified bitumens with similar high PG grades. Road Materials and Pavement Design, 16(2), 469-480. https://doi.org/10.1080/14680629.2014.995209.

Domingos, M. D. I. and Faxina, A. L. (2015b). Rheological analysis of asphalt binders modified with Elvaloy ${ }^{\circledR}$ terpolymer and polyphosphoric acid on the multiple stress creep and recovery test. Materials and Structures, 48(5), 1405-1416. https://doi.org/10.1617/s11527-013-0242-y.

Domingos, M. D. I., Faxina, A. L. and Bernucci, L. L. B. (2017). Characterization of the rutting potential of modified asphalt binders and its correlation with the mixture's rut resistance. Construction and Building Materials, 144, 207213.

https://doi.org/10.1016/j.conbuildmat.2017.03.1 71.

Dow. Dow chemicals brand index Elvaloy. (2021, February 02). Retrieved from https://www.dow.com/en-us/brand/elvaloy.html.

Dow. ELVALOYTM RET vs. SBS Modified Asphalt. (2021, February 02). Retrieved from https://www.dow.com/en-us/market/mktbuilding-construction/sub-build-constructionchem/app-build-constchem-asphaltmodification/ret-vs-sbs-modified-asphalt.html.

Gama, D. A., Yan, Y., Rodrigues, J. K. G. and Roque, R. (2018). Optimizing the use of reactive terpolymer, polyphosphoric acid and highdensity polyethylene to achieve asphalt binders with superior performance. Construction and Building Materials, 169, 522-529. https://doi.org/10.1016/j.conbuildmat.2018.02.2 06.

Geckil, T. (2019). Physical, chemical, microstructural and rheological properties of reactive terpolymer-modified bitumen. Materials, 12(6). https://doi.org/10.3390/ma12060921.

Geckil, T. and Seloglu, M. (2018). Performance properties of asphalt modified with reactive terpolymer. Construction and Building Materials, 173, 262-271. https://doi.org/10.1016/j.conbuildmat.2018.04.0 36.

Hafeez, I. and Kamal, M. A. (2009). A rheological comparison of hard grade binders with polymer modified bitumen under aged and unaged conditions. Materials Characterisation Iv: Computational Methods and Experiments, 64, 105-114. https://doi.org/10.2495/Mc090101.

Hampl, R., Vacin, O., Jasso, M., Stastna, J. and Zanzotto, L. (2015). Modeling of tensile creep and recovery of polymer modified asphalt binders at low temperatures. Applied Rheology, 25(3). https://doi.org/10.3933/Applrheol-2534675 .

Hesp, S. A. M., Hoare, T. R. and Roy, S. D. (2002). Low-temperature Fracture in Reactive-ethyleneterpolymer-modified Asphalt Binders. International Journal of Pavement Engineering, 3(3), 153-159. https://doi.org/10.1080/1029843021000067809.

Irfan, M., Saeed, M., Ahmed, S. and Ali, Y. (2017). Performance Evaluation of Elvaloy as a FuelResistant Polymer in Asphaltic Concrete Airfield Pavements. Journal of Materials in Civil Engineering, 29(10). https://doi.org/10.1061/(Asce)Mt.19435533.0002018

Isacsson, U. and Lu, X. (1995). Testing and appraisal of polymer-modified road bitumens - state-of-theart. Materials and Structures, 28(177), 139-159. https://doi.org/10.1007/Bf02473221.

Jasso, M., Hampl, R., Vacin, O., Bakos, D., Stastna, J. and Zanzotto, L. (2015). Rheology of conventional asphalt modified with SBS, Elvaloy and polyphosphoric acid. Fuel Processing Technology, 140, 172-179. https://doi.org/10.1016/j.fuproc.2015.09.002.

Javid, M. A. (2016). Effect of polymer modification on rheological properties of asphalt. Journal of Civil Engineering Research, 6(3), 55-60.

Keyf, S. (2010). Investigation of penetration and penetration index in bitumen modified with SBS and reactive terpolymer. Sigma, 28, 26-34.

Keyf, S. (2015). The modification of bitumen with reactive ethylene terpolymer, styrene butadiene styrene and variable amounts of ethylene vinyl acetate. Research on Chemical Intermediates, 
41(3),

1485-1497. https://doi.org/10.1007/s11164-013-1287-9.

Keyf, S. (2018). The modification of bitumen with styrene-butadiene-styrene, ethylene vinyl acetate and varying the amount of reactive ethylene terpolymer. Journal of Elastomers and Plastics, $50(3)$,

241-255. https://doi.org/10.1177/0095244317708590.

Keyf, S., Ismail, O. and Corbacioglu, B. D. (2007a). The modification of bitumen with synthetic reactive ethylene terpolymer and ethylene terpolymer. Petroleum Science and Technology, 25(5-6), 561-568

https://doi.org/10.1080/10916460500294259.

Keyf, S., Ismail, O. and Corbacioglu, B. D. (2007b). Polymer-modified bitumen using ethylene terpolymers. Petroleum Science and Technology, 25(7), 915-923. https://doi.org/10.1080/10916460500411812.

Li, X. J., Clyne, T., Reinke, G., Johnson, E. N., Gibson, N. and Kutay, M. E. (2011). Laboratory evaluation of asphalt binders and mixtures containing polyphosphoric acid. Transportation Research Record, 2210, 47-56. https://doi.org/10.3141/2210-06.

Liu, L. Q., Xiao, F. P., Zhang, H. L. and Amirkhanian, S. (2017). Rheological characteristics of alternative modified binders. Construction and Building Materials, 144, 442-450. https://doi.org/10.1016/j.conbuildmat.2017.03.1 93.

Lotader. Bitumen reactive modification with Lotader ${ }^{\circledR}$ AX range. (2021, February 02). Retrieved from https://www.lotader.com/en/application/bitumen -modification/.

Love, C. T., Xian, G. and Karbhari, V. M. (2007). Cathodic disbondment resistance with reactive ethylene terpolymer blends. Progress in Organic Coatings, 60(4), 287-296. https://doi.org/10.1016/j.porgcoat.2007.07.022.

Loyens, W. and Groeninckx, G. (2002). Ultimate mechanical properties of rubber toughened semicrystalline PET at room temperature. Polymer, 43(21), 5679-5691. https://doi.org/10.1016/S0032-3861(02)00472$\mathrm{X}$.

Michon, L. C., Williams, T. M. and Miknis, F. P. (1998). Use of the environmental scanning electron microscope to investigate three polymer modified asphalts. Petroleum Science and Technology, 16(7-8), 797-809. https://doi.org/10.1080/10916469808949812.

Miknis, F. P. and Thomas, K. P. (2008). NMR analysis of polyphosphoric acid-modified bitumens. Road
Materials and Pavement Design, 9(1), 59-72. https://doi.org/10.3166/Rmpd.9.59-72.

Minkova, L., Yordanov, H. and Filippi, S. (2002). Characterization of blends of LDPE and PA6 with functionalized polyethylenes. Polymer, 43(23), 6195-6204. https://doi.org/10.1016/S0032-3861(02)005323.

Oruc, S. and Yilmaz, B. (2016). Improvement in performance properties of asphalt using a novel boron-containing additive. Construction and Building Materials, 123, 207-213. https://doi.org/10.1016/j.conbuildmat.2016.07.0 03.

Oruc, S., Yilmaz, B. and Sancak, K. (2016). Effect of boron-containing additives on rheological properties of asphalt binder. Road Materials and Pavement Design, 17(4), 810-824. https://doi.org/10.1080/14680629.2015.1120228

Pazzagli, F. and Pracella, M. (2000). Reactive compatibilization of polyolefin/PET blends by melt grafting with glycidyl methacrylate. Macromolecular Symposia, 149(1), 225-230. https://doi.org/10.1002/15213900(200001)149:1<225::AIDMASY225>3.0.CO;2-8.

Pérez-Lepe, A., Martínez-Boza, F. J. and Gallegos, C. (2007). High temperature stability of different polymer-modified bitumens: A rheological evaluation. Journal of Applied Polymer Science, 103(2), 1166-1174. https://doi.org/10.1002/app.25336.

Perez-Lepe, A., Martinez-Boza, F. J., Gallegos, C., Gonzalez, O., Munoz, M. E. and Santamaria, A. (2003). Influence of the processing conditions on the rheological behaviour of polymer-modified bitumen. Fuel, 82(11), 1339-1348. https://doi.org/10.1016/S0016-2361(03)000656.

Polacco, G., Stastna, J., Biondi, D., Antonelli, F., Vlachovicova, Z. and Zanzotto, L. (2004a). Rheology of asphalts modified with glycidylmethacrylate functionalized polymers. Journal of Colloid and Interface Science, 280(2), 366-373. https://doi.org/10.1016/j.jcis.2004.08.043.

Polacco, G., Stastna, J., Vlachovicova, Z., Biondi, D. and Zanzotto, L. (2004b). Temporary networks in polymer-modified asphalts. Polymer Engineering and Science, 44(12), 2185-2193. https://doi.org/10.1002/pen.20246.

Selvavathi, V., Sekar, V. A., Sriram, V. and Sairam, B. (2002). Modifications of bitumen by elastomer and reactive polymer - A comparative study. 
Petroleum Science and Technology, 20(5-6), 535-547. https://doi.org/10.1081/Lft120003577.

Sengoz, B. and Isikyakar, G. (2008). Evaluation of the properties and microstructure of SBS and EVA polymer modified bitumen. Construction and Building Materials, 22(9), 1897-1905. https://doi.org/10.1016/j.conbuildmat.2007.07.0 13.

Sengoz, B. and Topal, A. (2005). Use of asphalt roofing shingle waste in HMA. Construction and Building Materials, 19(5), 337-346. https://doi.org/10.1016/j.conbuildmat.2004.08.0 05 .

Singh, D., Ashish, P. K., Chander, S., Habal, A. and Kataware, A. (2019a). Effect of warm-mix additives and lime on intermediate-temperature fracture property of RET- and PPA-modified asphalt binder. Journal of Materials in Civil Engineering, $\quad 31(7), \quad 04019112$. https://doi.org/10.1061/(Asce)Mt.19435533.0002756 .

Singh, D., Ashish, P. K., Kataware, A. and Habal, A. (2017). Evaluating performance of PPA-andElvaloy-modified binder containing WMA additives and lime using MSCR and LAS tests. Journal of Materials in Civil Engineering, 29(8). https://doi.org/10.1061/(Asce)Mt.19435533.0001934 .

Singh, D., Ashish, P. K., Kataware, A. and Habal, A. (2019b). Effects of WMA additives and hydrated lime on high-stress and high-temperature performance of Elvaloy ${ }^{\circledR}$ - and PPA-modified asphalt binder. Road Materials and Pavement Design, 20(6), 1354-1375. https://doi.org/10.1080/14680629.2018.1446040

Singh, D., Habal, A., Ashish, P. K. and Kataware, A. (2018). Evaluating suitability of energy efficient and anti-stripping additives for polymer and Polyphosphoric acid modified asphalt binder using surface free energy approach. Construction and Building Materials, 158, 949-960. https://doi.org/10.1016/j.conbuildmat.2017.10.0 79.

Skronka, G., Jasso, M. and Vacin, O. 2019. Determination of rutting distresses on hot mix asphalts by advanced techniques MATEC Web of Conferences, EDP Sciences.

Suo, Z. and Wong, W. G. (2009). Nonlinear properties analysis on rutting behaviour of bituminous materials with different air void contents. Construction and Building Materials, 23(12), 3492-3498. https://doi.org/10.1016/j.conbuildmat.2009.07.0 04.

Tayfur, S., Ozen, H. and Aksoy, A. (2007). Investigation of rutting performance of asphalt mixtures containing polymer modifiers. Construction and Building Materials, 21(2), 328-337. https://doi.org/10.1016/j.conbuildmat.2005.08.0 14.

Topal, A. (2010). Evaluation of the properties and microstructure of plastomeric polymer modified bitumens. Fuel Processing Technology, 91(1), 45-51. https://doi.org/10.1016/j.fuproc.2009.08.007.

Vachhani, K. K. and Mishra, C. (2014). Influence of VG30 grade bitumen with and without reactive ethylene terpolymer (Elvaloy $\left.{ }^{\circledR} 4170\right)$ in short term aging. International Journal of Current Engineering and Technology, 4(6), 4206-4209.

Xu, C., Zhang, Z. Q. and Liu, F. F. (2020). Improving the low-temperature performance of RET modified asphalt mixture with different modifiers. Coatings, 10(11), 1070. https://doi.org/10.3390/coatings10111070.

Xu, C., Zhang, Z. Q., Zhao, F. Q., Liu, F. F. and Wang, J. R. (2019). Improving the performance of RET modified asphalt with the addition of polyurethane prepolymer (PUP). Construction and Building Materials, 206, 560-575. https://doi.org/10.1016/j.conbuildmat.2019.02.1 01 .

Yildirım, Y. (2007). Polymer modified asphalt binders. Construction and Building Materials, 21(1), 6672. https://doi.org/10.1016/j.conbuildmat.2005.07.0 07 .

Yilmaz, M., Kok, B. V. and Kuloglu, N. (2011). Effects of using asphaltite as filler on mechanical properties of hot mix asphalt. Construction and Building Materials, 25(11), 4279-4286. https://doi.org/10.1016/j.conbuildmat.2011.04.0 72.

Zahoor, M., Nizamuddin, S., Madapusi, S. and Giustozzi, F. (2021). Sustainable asphalt rejuvenation using waste cooking oil: A comprehensive review. Journal of Cleaner Production, 278. https://doi.org/10.1016/j.jclepro.2020.123304.

Zhu, J. Q., Birgisson, B. and Kringos, N. (2014). Polymer modification of bitumen: Advances and challenges. European Polymer Journal, 54, 1838 . https://doi.org/10.1016/j.eurpolymj.2014.02.005 